\title{
A Iconicidade na criação de termos técnicos em Libras
}

\author{
André Nogueira Xavier ${ }^{1}$ \\ Thyago Santos ${ }^{2}$
}

Resumo: Taub (2004) propõe um modelo para explicar a iconicidade linguística. Esse modelo envolve três estágios: a seleção imagética, a esquematização e a codificação. O primeiro estágio consiste na seleção de aspectos do referente que se quer expressar linguisticamente. O segundo se refere à redução desses aspectos a um esquema que retém somente as relações estruturais fundamentais de suas partes. $O$ terceiro consiste na seleção dos recursos fonéticos apropriados para a manifestação linguística de um dado conceito. À luz desse modelo, analisamos um processo de criação de termos técnicos na Libras para designar o mosquito Aedes aegypti e os vírus por ele transmitidos. Os dados foram coletados de uma interação entre nove surdos e um biólogo ouvinte em um grupo do aplicativo Telegram. Os resultados indicam que a seleção imagética e a esquematização foram influenciadas pelas imagens da estrutura viral, apresentadas e explicadas pelo biólogo, e que a codificação envolveu fatores articulatórios e perceptuais.

Palavras-chave: Iconicidade. Criação lexical. Termos técnicos. Libras.

1 Professor Doutor do curso de licenciatura em Letras-Libras da Universidade Federal do Paraná (UFPR). E-mail: andrexavier@ufpr.br.

2 Pesquisador colaborador do projeto "A Libras à luz da linguística cognitiva", registrado no Banpesq/Thales: 2016023729 e coordenado pelo Prof. Dr. André Xavier (UFPR). E-mail: thysants@outlook.com. 
Abstract: Taub (2004) proposes a model to explain the linguistic iconicity. This model involves three stages: image selection, schematization and encoding. The first stage consists of selecting aspects of the referent one wants to express linguistically. The second one refers to the reduction of those aspects to a scheme that keeps their fundamental structural relationship. The third stage consists of selecting the appropriate phonetic resources for the linguistic manifestation of a concept. In light of Taub's model, we have analyzed the creation of technical terms in Libras to refer to Aedes aegypti and the viruses it transmits. The data was collected from an interaction involving nine deaf individuals and one hearing biologist in a Telegram group. The results indicate that image selection and schematization were influenced by the viral structure images shown and explained by the biologist. In addition, they showed that encoding involved articulatory and perceptual factors.

Keywords: Iconicity. Lexical creation. Technical terms. Libras.

\section{Introdução}

Para Saussure (2006 [1916]), a língua é um sistema de signos, entidades psíquicas formadas de uma face conceitual, o significado, e outra acústica, o significante. Segundo o autor, o laço que une essas duas grandezas linguísticas é arbitrário, ou seja, a sequência de fonemas empregada para se referir a um determinado conceito não é motivada por qualquer de seus aspectos. Isso fica patente quando se observa que línguas diferentes expressam um mesmo significado através de significantes distintos.

Saussure reconhece, no entanto, a existência das onomatopeias, signos linguísticos cujo significante é icônico, ou seja, motivado por seu significado. Apesar disso, o autor sustenta que as onomatopeias "não são apenas pouco numerosas, mas sua escolha é já, em certa medida, arbitrária, 
pois que não passam de imitação aproximativa e já meio convencional de certos ruídos (compare-se o francês onaona e o alemão wauwau" 3 (SAUSSURE, 2006 [1916], p. 83) ${ }^{4}$.

Essa visão explica, em parte, a negação, por muito tempo, do estatuto de língua natural das línguas de sinais pela ciência linguística. A té o trabalho de Stokoe (1960), a expressiva iconicidade observada, sobretudo, no nível lexical de tais línguas era tomada como sinal de sua inferioridade e ausência de uma estrutura linguística subjacente (LANE, 1992).

Por essa razão, de acordo com Taub (2012), alguns dos primeiros linguistas a investigar línguas sinalizadas se dedicaram a demonstrar a irrelevância da iconicidade, com o objetivo de aproximar essas línguas das línguas orais e, assim, defender seu estatuto de língua natural. Alguns pesquisadores, entretanto, dedicaram-se a entender o funcionamento da iconicidade nas línguas sinalizadas e a descrever suas várias formas de manifestação. Entre estes estão Klima e Bellugi (1979), cujo trabalho evidenciou que a iconicidade nas línguas de sinais é regida pela sua gramática.

Foi somente com o surgimento de correntes linguísticas como a funcionalista e a cognitiva que se começou a dar uma maior atenção à iconicidade nas línguas orais. No plano sonoro, estudos revelaram que as palavras onomatopaicas exibem sistematicidade e conformidade ao sistema fonológico da língua a que pertencem (HINTON; NICHOLS; OHALA, 1994). No plano morfossintático, estudos mostraram que a ordem de palavras nas frases ou de morfemas em palavras de línguas polissintéticas é motivada pela ordem dos eventos expressos ou por proximidade conceitual daqueles (HAIMAN,1985).

Nesse cenário, a iconicidade nas línguas de sinais também ganha um novo olhar. Para Taub (2012), a motivação dos sinais não se resume

3 Em português, a onomatopeia que corresponde à vocalização de cachorros é "au-au".

4 Saussure reconhece casos de arbitrariedade relativa, nos quais o signo linguístico apresenta algum grau de motivação. Um exemplo é o signo "dezenove" que, diferentemente de "vinte", totalmente arbitrário, evoca o significado das partes que o compõem, "dez" e "nove". 
a uma relação objetiva entre forma linguística e referente ${ }^{5}$, dado que, se assim fosse, mesmo indivíduos não sinalizantes seriam capazes de apreender essa relação e deduzir o significado de qualquer sinal. Com base nisso, Taub propõe que a iconicidade linguística é uma manifestação de uma capacidade cognitiva mais geral que nos permite estabelecer relações de semelhança entre imagens mentais. De acordo com a autora, "essas relações são motivadas parcialmente por experiências comuns a todos os humanos e parcialmente por experiências particulares a culturas e sociedades específicas" (TAUB, 2012, p. 390). Isso explica, por exemplo, por que palavras icônicas, embora apresentem formas motivadas pela semelhança com seu referente, não são universais. Isso parece explicar também por que as línguas de sinais são mais icônicas do que as línguas orais.

Como aponta Taub, a maioria dos conceitos não apresenta imagens sonoras associadas a eles. Tal fato acaba impedindo que as línguas orais os representem iconicamente. Diferentemente, a maior parte dos conceitos tem imagens visuais, espaciais e motoras que podem ser exploradas por línguas visuais. Tome-se como exemplo o conceito "mesa" que, apesar de não contar com imagens sonoras associadas a ele, possui imagens visuais relativas a seu formato. Nesse sentido, segundo Taub (2012), a presença relativamente menor de iconicidade nas línguas orais não lhes confere superioridade em relação às línguas sinalizadas. Ao contrário, indica a incapacidade das línguas orais de fazer uso desta - que talvez seja um princípio universal nas línguas -, em virtude da pobreza de imagens sonoras em nossa experiência.

O objetivo geral deste artigo é explorar a iconicidade lexical em Libras. Porém, diferentemente dos trabalhos feitos sobre o tema em outras línguas sinalizadas (KLIMA; BELLUGI, 1979), pretende-se

5 Diferentemente de Saussure, que olhava exclusivamente para a relação entre significante e significado, outras teorias, entre as quais a linguística cognitiva na qual se baseia Taub, olham não só para o significado, mas também para a relação entre significado e referente em um mundo cognizado. 
analisar o papel da iconicidade em um processo de criação lexical, e não simplesmente no seu produto. Especificamente, analisa-se um processo de criação de termos técnicos na Libras para designar o mosquito Aedes aegypti e os vírus por ele transmitidos. Para isso, elegeu-se o modelo de construção analógica da iconicidade linguística proposto por Taub (2004) e analisaram-se dados coletados de uma situação real e colaborativa de criação lexical em Libras. O modelo de Taub é sumarizado na seção seguinte, "Fundamentação teórica", os dados são descritos na seção "Metodologia" e sua análise, apresentada nas subseções "Resultados" e "Discussão".

\section{Fundamentação Teórica}

Nesta seção, sumariza-se o modelo de construção analógica da iconicidade linguística proposto por Taub (2004). Esse modelo pretende oferecer um conjunto de ferramentas para a descrição, o modelamento e a análise da criação de itens linguísticos icônicos pertencentes a qualquer nível estrutural tanto de línguas de sinais quanto de línguas orais. A autora descreve seu modelo como um desdobramento mais abrangente de trabalhos pioneiros sobre a iconicidade nas línguas de sinais, entre os quais cita DeMatteo (1977), Brennan (1980), Boyes-Braem (1981) e Liddell (1992). Além disso, segundo a autora, seu modelo incorpora trabalhos em semântica realizados no âmbito da linguística cognitiva, entre os quais cita Lakoff e Johnson (1980), Langacker (1987) e Fauconnier (1997).

No modelo de Taub, a criação de itens icônicos envolve três estágios: a seleção imagética, a esquematização e a codificação. O primeiro estágio consiste na seleção de uma imagem mental para o conceito que se quer representar linguisticamente. Essa seleção parece ser guiada pela modalidade da língua, dado que, a despeito da multimodalidade das 
imagens associadas a um determinado conceito, línguas de sinais elegem imagens visuais, espaciais ou motoras, ao passo que línguas orais elegem imagens sonoras.

Concretamente, apesar de haver imagens de diferentes naturezas associadas, por exemplo, ao conceito "árvore" (olfativas, táteis, auditivas - para ouvintes -, cinestésicas e visuais), observa-se que línguas de sinais diferentes tendem a escolher imagens visuais para representá-los. De forma análoga, embora haja imagens de diferentes ordens associadas, por exemplo, ao conceito "som da campainha", vê-se que línguas orais diversas tendem a selecionar imagens sonoras associadas a ele.

Independentemente da modalidade da imagem selecionada, toda a sua riqueza de detalhes não pode ser linguisticamente representada. Não seria possível para as línguas de sinais, por exemplo, representar iconicamente as cores das folhas, do caule e do solo presentes em sua imagem visual. Analogamente, seria inviável paras as línguas orais representar todas as propriedades acústicas presentes na imagem sonora associada ao som da campainha. Como se sabe, esse som é produzido por instrumentos materialmente muito distintos das estruturas corpóreas empregadas na articulação de sons linguísticos.

Isso impõe ao processo de criação de itens icônicos a necessidade de esquematização, ou seja, de reinterpretação da imagem (visual, espacial, motora ou acústica) em termos das categorias semânticas com as quais uma determinada língua opera. A análise da forma do sinal ÁRVORE da ASL (Figura 1), por exemplo, sugere que a esquematização da imagem que ele representa envolveu a interpretação desta em três categorias semânticas: "ramificação", "suporte alto e fino" e "superfície plana". 
Figura 1 - Correspondências entre aspectos imagéticos do conceito "árvore" e o sinal que o representa em ASL

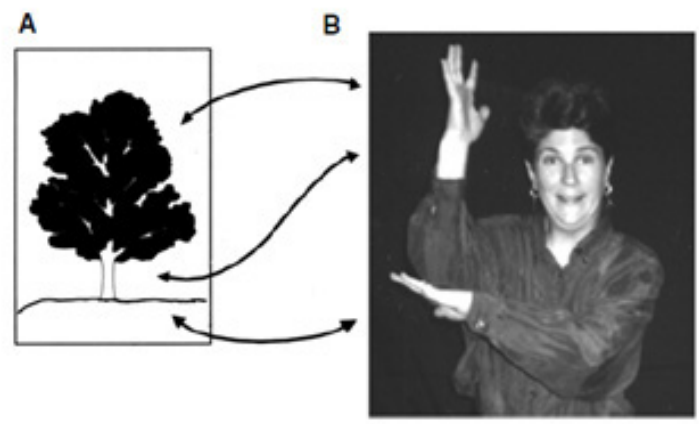

Fonte: Taub (2004, p. 29).

Já a análise da palavra onomatopaica "ding”, do inglês, que expressa o som produzido pela campainha, sugere que sua imagem auditiva, representada em (2) por meio de suas ondas sonoras, foi reinterpretada em termos das categorias "início abrupto", "seção intermediária aguda" e "esmaecimento gradual”. Isso é evidenciado pelos sons daquela língua que as representam, respectivamente, o som oclusivo /d/, a vogal alta /i/ e a consoante nasal velar $/ \mathrm{g} /$.

Figura 2 - Correspondências entre as ondas sonoras produzidas por um sino japonês e a palavra onomatopaica "ding" pronunciada por uma mulher norte-americana

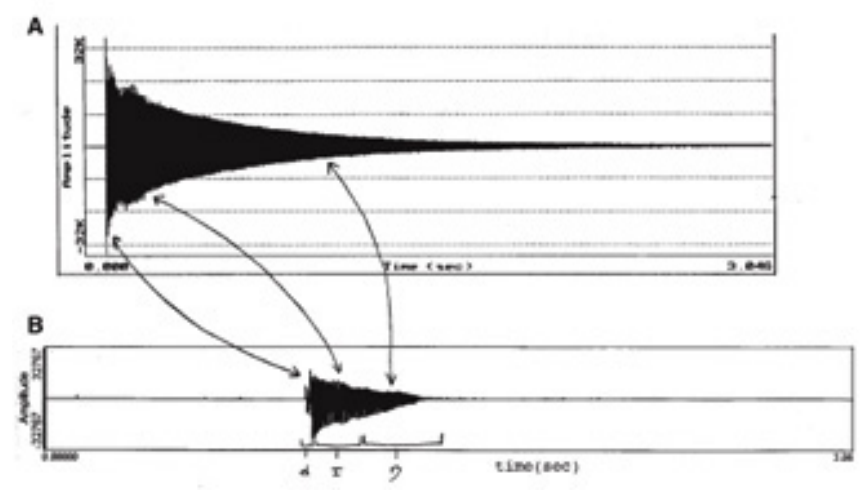

Fonte: Taub (2004, p. 20). 
A seleção dos recursos fonéticos do inglês citados acima para representar o som da campainha ocorre no terceiro estágio da criação de itens icônicos no modelo de Taub (2004): a codificação. No exemplo da ASL, esse processo resultou na seleção da "mão dominante aberta", "antebraço da mão dominante na vertical" e "antebraço da mão não-dominante na horizontal" para representar, respectivamente, as categorias semânticas "ramificação", "suporte alto e fino" e "superfície plana".

$\mathrm{Na}$ codificação, segundo Taub, existem dois níveis nos quais escolhas um tanto quanto arbitrárias são feitas. Em um primeiro nível, observa-se que são selecionados recursos fonéticos dentre outros igualmente disponíveis e teoricamente possíveis. A autora ilustra tal fato com o sinal DIPLOMA da ASL, cuja realização, como sugere a Figura 3, consiste em mover retilineamente para lados opostos cada uma das mãos, configuradas de tal forma que o polegar e o indicador se toquem pelas pontas, enquanto os demais se encontram distendidos e espalmados.

Figura 3 - Sinal DIPLOMA da ASL
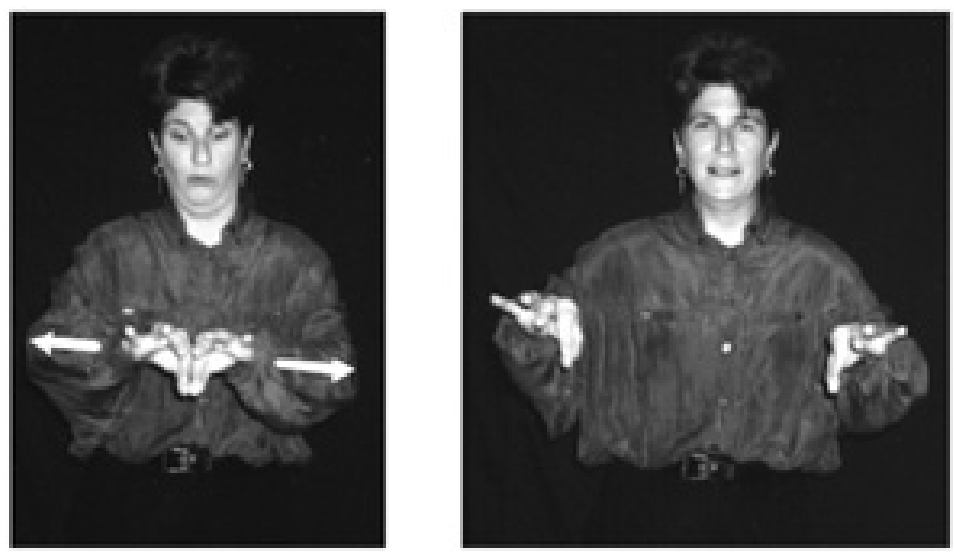

Fonte: Taub (2004, p. 31). 
A configuração e o movimento das mãos descrevem, nesse sinal, o formato de um diploma em rolo. Segundo Taub, em tese, outras configurações de mão da ASL poderiam ter sido selecionadas, ou seja, o formato cilíndrico poderia ter sido descrito por uma configuração em que o contato com o polegar é feito com o dedo médio, com o anelar ou com o mínimo.

Além do nível das unidades sublexicais, a relativa arbitrariedade no processo de codificação se manifesta também na escolha de unidades icônicas lexicais. Como aponta Taub, usuários da ASL poderiam criar sinais icônicos diferentes para representar o conceito "árvore". Poderiam, por exemplo, configurar uma das mãos em 1 (dedo indicador distendido e demais fechados) para representar o caule e colocar sobre ela a outra, com os dedos espalmados, mas flexionados nas juntas distais e proximais, para representar a copa.

O mesmo pode ser observado no processo de codificação em línguas orais. No lugar de /d/ em "ding", outros sons do inglês poderiam ter sido escolhidos para obter os mesmos efeitos. Poder-se-ia empregar, por exemplo, /t/ ou /p/ ("ting", "ping"), para representar o início abrupto do som da campainha. Além disso, onomatopeias diferentes poderiam ser empregadas para representar, no lugar da forma convencional "splash", o som de um objeto caindo na água. Poder-se-ia usar, por exemplo, "katoosh". Conforme diz Taub, a escolha de uma forma e sua consequente convencionalização devem decorrer de fatores diversos, entre os quais a autora cita a facilidade de articulação.

Vale lembrar que as etapas do modelo de construção analógica de Taub estão ligadas a processos cognitivos mais gerais. A seleção imagética, por exemplo, pode ser entendida como um processo metonímico, dado que consiste na seleção de uma imagem mental dentre as várias associadas a um conceito para representá-lo como um todo. Interessantemente, observa-se também nesse processo o efeito de prototipicidade. Apesar de existirem, por exemplo, árvores de diferentes tamanhos e formas, o 
sinal da ASL revela a seleção de uma árvore típica para norte-americanos. A esquematização e a codificação, por sua vez, podem ser vistas como resultantes de um processo de categorização, uma vez que consistem, respectivamente, na interpretação da imagem selecionada em termos das categorias semânticas com as quais a língua opera e na seleção das categorias fonéticas da língua que mais apropriadamente podem representá-las.

Os diagramas a seguir ilustram os três estágios envolvidos na criação de um item linguístico icônico, tal como proposto no modelo de construção analógica de Taub (2004). Esquematiza-se, no primeiro deles (Figura 4), como esse processo provavelmente se deu na formação do sinal ÁRVORE da ASL e, no segundo (Figura 5), como deve ter ocorrido na formação da palavra "ding", do inglês.

Figura 4 - Ilustração do modelo de construção analógica da iconicidade linguística proposto por Taub, por meio de um sinal da ASL

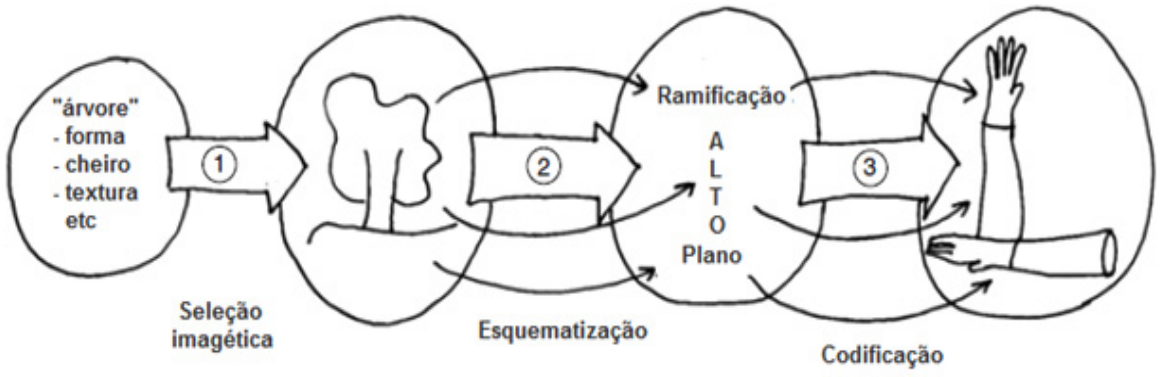

Fonte: Taub (2004, p. 44). 
Figura 5 - Ilustração do modelo de construção analógica da iconicidade linguística proposto por Taub, por meio de uma palavra do inglês

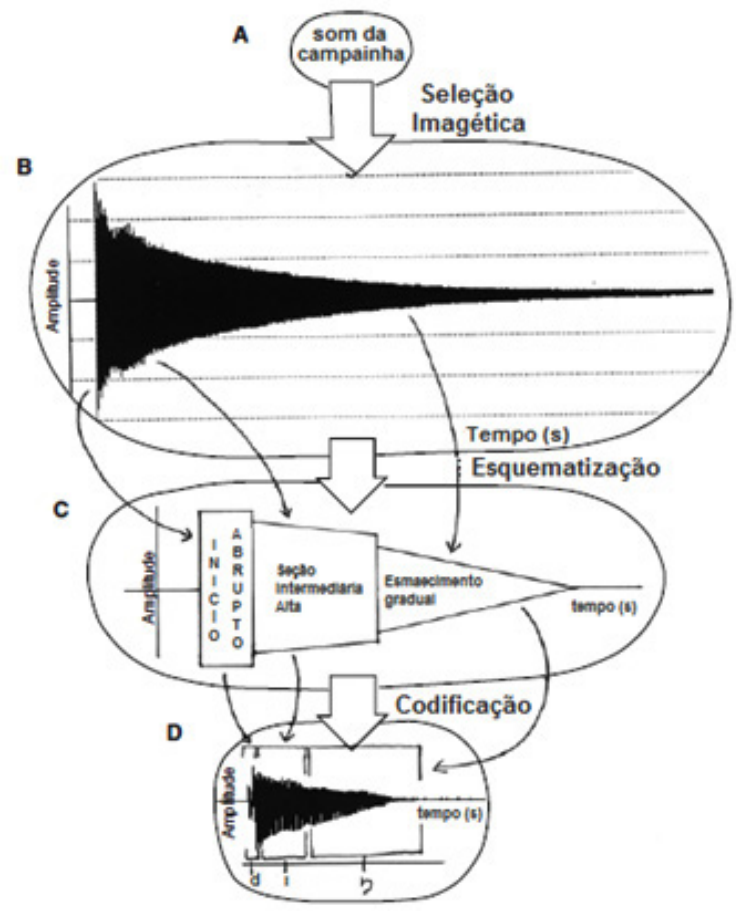

Fonte: Taub (2004, p. 52).

Taub ressalta, no entanto, que seu modelo não objetiva representar o que se passa na mente dos usuários de uma língua quando estes usam um item linguístico icônico. Seu modelo tem como propósito descrever os processos envolvidos na criação da iconicidade linguística, daí sua escolha como arcabouço teórico para este trabalho. Além disso, a autora frisa que a apresentação dos três estágios que propõe em sequência tem finalidade didática. Ela considera possível que os processos cognitivos que eles envolvem ocorram simultaneamente quando da criação de itens linguísticos icônicos. 


\section{Metodologia}

Os dados analisados neste trabalho provêm de uma discussão em Libras realizada por dez participantes (nove surdos e um ouvinte), por meio de um grupo no Telegram (aplicativo para celulares que permite a troca de mensagens em áudio e/ou vídeo) entre os meses de fevereiro e março de 2015. Essa discussão, que durou cerca de uma semana, girou em torno da criação de sinais para o mosquito Aedes aegypti e para os vírus que ele transmite e causam as doenças zika, chikungunya e dengue. Ela teve como objetivo atender a uma demanda da comunidade surda: a falta de uma forma padronizada de se referir ao mosquito e aos vírus mencionados, constantemente citados na mídia na época.

Em relação aos participantes surdos, sete são paulistas e residentes na cidade de São Paulo; um é mineiro e reside na cidade de Viçosa (MG); e outro carioca, mas residente em João Pessoa (PB). Todos eles têm nível superior: três são formados em Pedagogia; três, em Letras-Libras; dois, em ambos; e um, em Gastronomia, mas cursando Letras-Libras na época da discussão. Todos atuam como professores de Libras: três deles no ensino superior e os demais na educação de crianças surdas. O participante ouvinte, por sua vez, é paulista e reside na cidade de São Paulo. Ele é formado em Biologia e atua como professor de surdos e tradutor-intérprete de Libras/Português.

As contribuições de todos os participantes foram reunidas, na ordem em que foram realizadas, em um único vídeo, cuja duração final é de 57'38". É importante ressaltar que o uso dos dados aqui analisados foi formalmente autorizado por todos os seus participantes, por meio da assinatura de um termo de consentimento esclarecido.

O exame do vídeo que reuniu toda a discussão foi realizado por meio do software Elan, que permitiu não apenas visualizá-lo de forma mais cuidadosa por meio da redução da velocidade de sua exibição, mas também realizar anotações que subsidiaram nossa análise. 


\section{Resultados}

Embora o vídeo que reuniu todas as contribuições dos dez participantes tenha 57’38” de duração, sua análise nos levou a desconsiderar 11'39", em razão de algumas participações não estarem diretamente relacionadas à criação dos sinais para o $A$. aegypti e para os vírus transmitidos por ele, a saber, o vírus da zika, da chikungunya e da dengue. Sendo assim, este trabalho se baseia em 45'99" da discussão original. Os trechos examinados contêm 30 contribuições que, como mostra o gráfico em (6), se apresentam mais concentradas em alguns participantes do que em outros. Apesar disso, o impacto da contribuição de cada participante no processo de criação lexical em análise não é diretamente proporcional à sua frequência de participação em todos os casos. Nakasato, por exemplo, participou uma única vez, mas uma de suas propostas foi muito bem aceita pelo grupo e acabou se tornando a eleita.

Figura 6 - Número de vídeos enviados por participante (S: surdo; O: ouvinte)

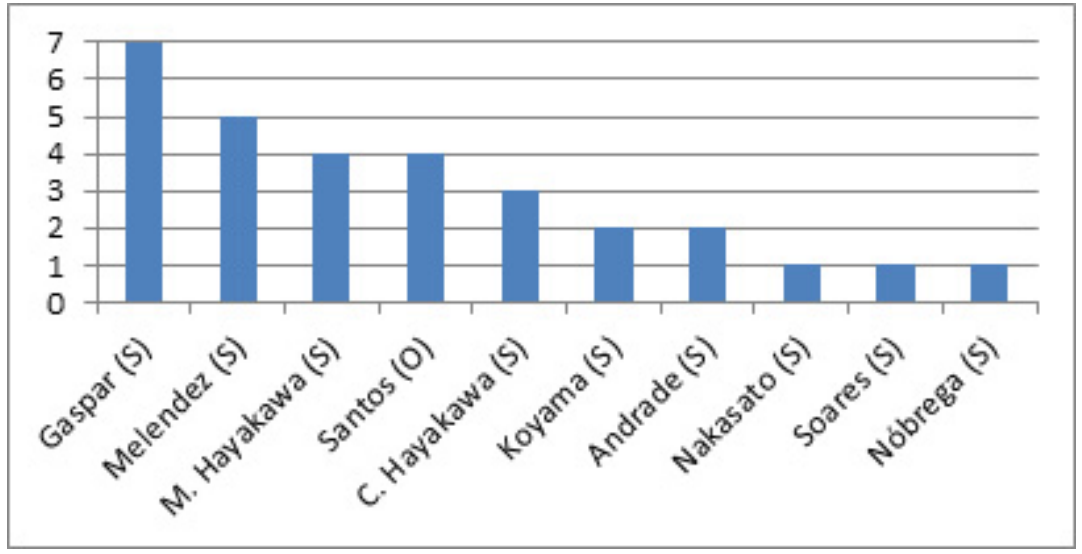

Fonte: Produzida pelos autores 
A discussão foi motivada pela propagação na comunidade surda de neologismos conceitualmente incorretos para designar o $A$. aegypti e os vírus que ele transmite. Tal fato é ilustrado no primeiro vídeo de Santos, o biólogo ouvinte, quando este cita o sinal em (7), e no único vídeo considerado de Soares, quando este questiona se os sinais em (8) são adequados para se referir à zika e à chikungunya.

Figura 7 - Neologismo para o A. aegypti

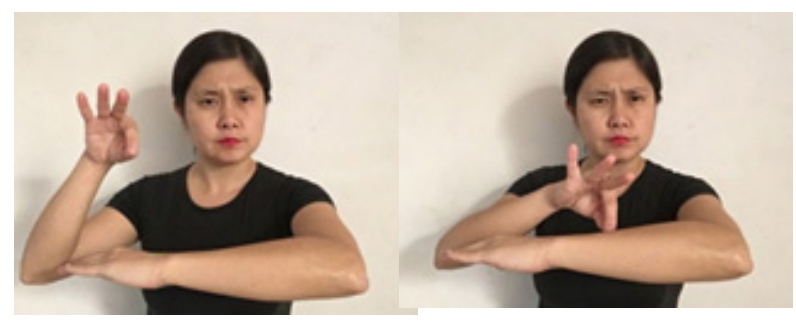

MOSQUITO

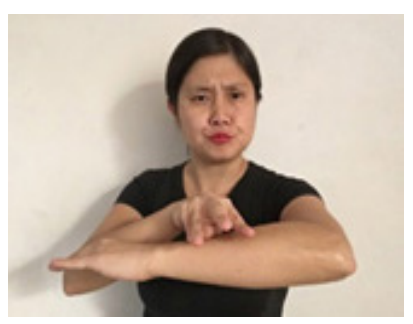

SAIR-TRÊS

Fonte: Produzida por Cláudia Hayakawa

Figura 8 - Neologismos para zika (a) e chikungunya (b)

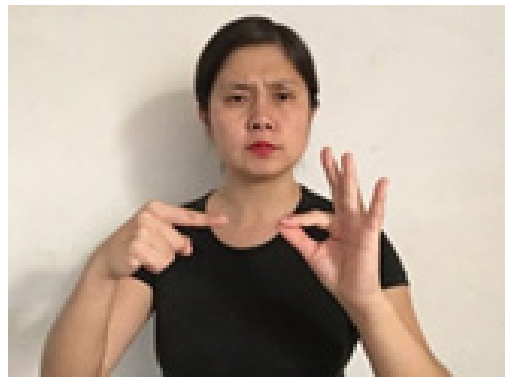

(a)

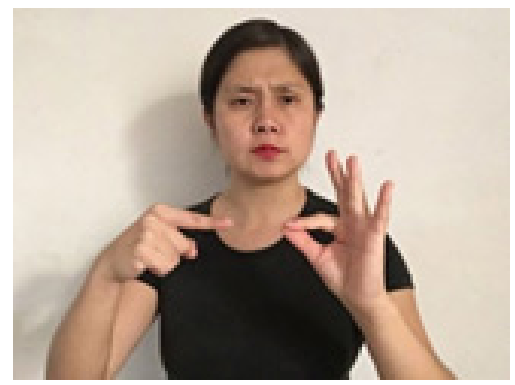

(b)

Fonte: Produzida por Cláudia Hayakawa

${ }^{6}$ Agradecemos à Cláudia Hayakawa por muito gentilmente se fotografar realizando os sinais aqui discutidos e ceder sua imagem para sua ilustração neste trabalho. Com isso, pudemos garantir maior qualidade das imagens, em relação às que obteríamos por meio de print screen de frames do vídeo em que foram originalmente produzidos. 
Conforme explica Santos, o problema do sinal em (7) diz respeito ao fato de mosquito e vírus não estarem dissociados. Essa indissociação é expressa pela composição do neologismo, formado a partir do sinal MOSQUITO e do sinal SAIR-TRÊS, referente aos vírus da zika, da chikungunya e da dengue. Como se sabe, os vírus transmitidos pelo $A$. aegypti podem, ainda que mais raramente, ser transmitidos por outro mosquito: o $A$. alpictus. Nesse sentido, é incorreto associar os vírus em questão exclusivamente a ele. Somando-se a isso, sabe-se que o $A$. aegypti também transmite o vírus da febre amarela e que não transmite todos os vírus ao mesmo tempo. Dessa forma, o uso de SAIR-TRÊS não é preciso, tanto por sugerir que apenas o mosquito em discussão transmite os vírus mencionados quanto por sugerir que só transmite esses três e o faz a uma só vez.

Em relação aos sinais citados por Soares, o problema está no atrelamento do mosquito a um vírus ou a uma doença específica. Como se pode ver nas imagens em (8), à base comum (versão do sinal MOSQUITO realizada sem movimento pela mão esquerda), agrega-se uma espécie de diacrítico (movimento em zigue-zague feito pela mão direita no sinal para a zika e apontamento repetido para a região das pontas do indicador e polegar no sinal também feito pela mão direita no sinal para a chikungunya). Com isso, os sinais sugerem que cada vírus tem um transmissor único e diferente, o que, como vimos, não corresponde à realidade.

Diante disso, Santos solicita aos participantes do grupo que criem novos sinais para o $A$. aegypti e para o vírus da zika, da chikungunya e da dengue, muito citados nas mídias naquele momento por conta de um aumento no número de pessoas infectadas por eles. Ele sugere que essa criação lexical se paute nos aspectos visuais tanto da foto do mosquito (Figura 9) quanto das imagens que ilustram a estrutura de cada vírus (Figura 10), enviadas por ele ao grupo. 


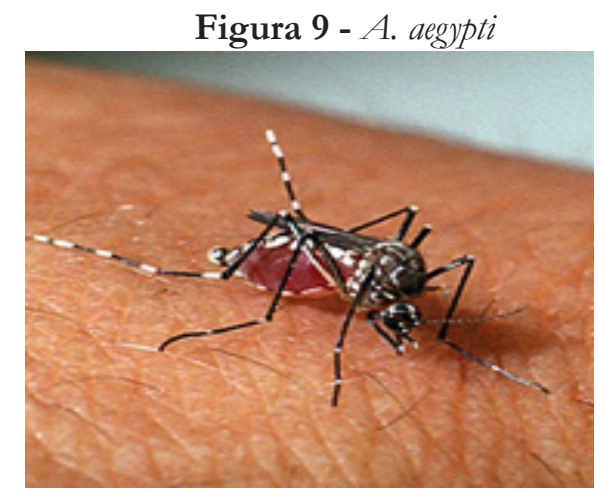

Fonte: Disponível em <http://www.manualdomundo.com.br/2015/05/cientistascriam-mosquito-da-dengue-femea-macho/ $>$

Figura 10 - Imagens-fantasia da estrutura do vírus da zika (a), do vírus da chikungunya (b) e do vírus da dengue (c) ${ }^{7}$

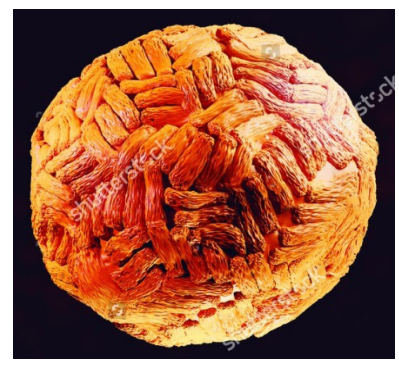

(a)

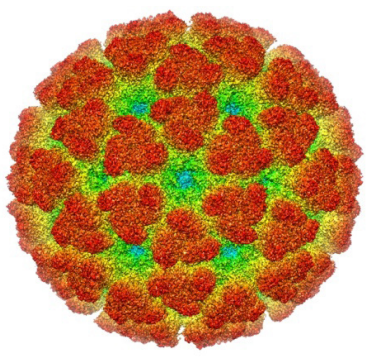

(b)

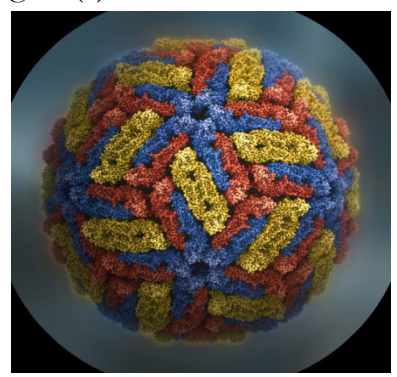

(c)

Fonte: Disponível em: <http://tinyurl.com/y7bnlgo9> (a); <http://tinyurl.com/ yb9tu87h > (b); <http://tinyurl.com/ybmlqyvv> (c).

Nos dados analisados, foram identificadas quatro propostas diferentes para o $A$. aegypti, uma para o vírus da zika, três para o vírus da chikungunya e quatro para o vírus da dengue. Nas imagens em (11),

${ }^{7}$ Imagens das estruturas virais baseadas em microscopia eletrônica e coloridas artificialmente. 
listam-se os sinais propostos para o $A$. aegypti. Como se pode ver, o primeiro consiste na junção do sinal MOSQUITO, já existente, com um novo sinal que, segundo sua criadora, Gaspar, representa, através da configuração de mão (CM) em 3 (dedos polegar, indicador e médio distendidos e demais fechados), as patas do inseto (11a). Esse mesmo sinal foi produzido por Andrade sem a primeira parte (11b). Vê-se também outra forma baseada no sinal MOSQUITO (11c). Nesse caso, o sinal é produzido, sem movimento, pela mão não dominante, enquanto a mão dominante, com dedos indicador e médio em gancho e demais fechados, toca pelas pontas a lateral daquela mão várias vezes para representar, conforme explica sua proponente, C. Hayakawa, as pintas brancas presentes no corpo do $A$. aegypti. O terceiro sinal (11d) foi originalmente proposto por Nakasato. Segundo ele, quatro dos dedos representam as patas ou os vírus que o mosquito em questão transmite (dedos mínimo, anelar, indicador e polegar) e um (dedo médio) o aparato bucal (probóscide). A quarta e última forma, e que acabou sendo a eleita, consiste em uma junção do sinal criado por Nakasato e do diacrítico proposto por C. Hayakawa (11e). Apesar das advertências de $\mathrm{C}$. Hayakawa quanto à necessidade de o toque da mão dominante ser repetido algumas vezes, observa-se a produção desse mesmo sinal, inclusive no vídeo que foi a público, com apenas um toque. Observa-se também, ao longo da discussão, a realização desse sinal sem o diacrítico $(11 \mathrm{~g})$. 
Figura 11 - Sinais propostos para o $A$. aegypti

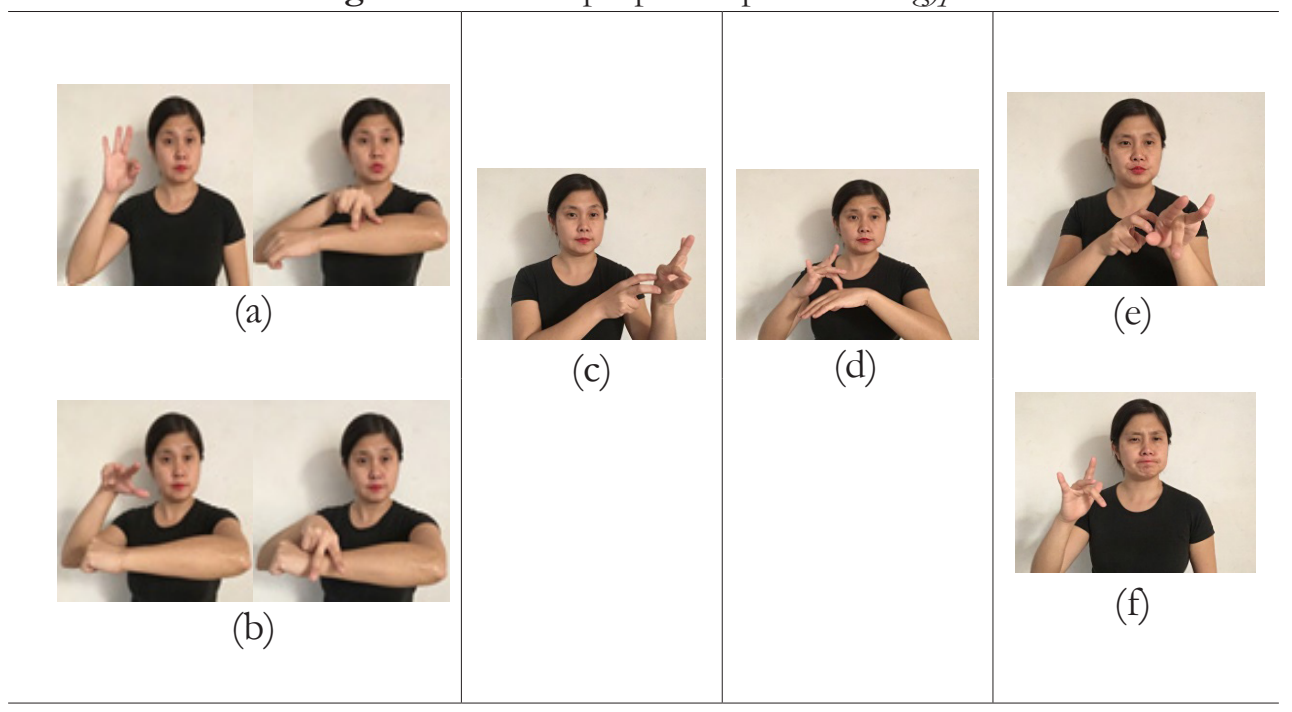

Fonte: Produzida por Cláudia Hayakawa

Em relação aos vírus, foram propostas as formas apresentada na Figura 12, a seguir. Como se pode observar, para o vírus da zika, o único sinal sugerido por Koyama consiste em tocar várias vezes a mão ativa em M (dedos indicador, médio e anelar distendidos e unidos e demais fechados) sobre o dorso da mão passiva em S (todos os dedos fechados) (12a). Conforme explica seu criador, a seleção dessa CM é motivada pela disposição das proteínas que envolvem o vírus da zika (Figura 10a). Já para o vírus da chikungunya, veemse três formas. A primeira, proposta por Gaspar, envolve o uso da CM em 5 com os dedos em gancho para representar o aspecto de couve-flor da camada proteica de tal vírus (12b). As duas últimas, sugeridas por Nakasato, diferem entre si no número de CMs e no movimento. Enquanto na proposta em (12c) vê-se a mão ativa mover-se da lateral da mão passiva, configurar em $\mathrm{O}$ (dedos unidos pelas pontas) para sua frente e durante esse movimento mudar sua configuração de $\mathrm{O}$ para a configuração em 5 (dedos abertos e espalmados), na proposta em (12d) vê-se a mão ativa em 5 tocar o dorso da mão passiva em $\mathrm{O}$ 
duas vezes. Por fim, para o vírus da dengue, foram atestadas quatro propostas diferentes. A primeira, sugerida por Gaspar, consiste em tocar a mão ativa, configurada em 3 , várias vezes sobre o dorso da mão passiva, configurada em $\mathrm{S}$ (12e). A escolha dessa CM foi motivada pela disposição, em formato de estrela, das proteínas na camada envoltória do vírus da dengue (Figura 10c). Como se pode ver em (12f), Nakasato realiza essa forma de maneira alternativa: com o polegar e os dedos indicador e médio flexionados nas juntas proximais. A segunda proposta de sinal para o vírus da dengue foi feita por C. Hayakawa e difere da anterior unicamente pelo uso de uma configuração de mão em que os dedos estão distendidos, para, assim, segundo ela, poder representar as cinco pontas da estrela $(12 \mathrm{~g})$. M. Hayakawa faz uma proposta alternativa, na qual a mão aparece configurada em 5 com os dedos envolvendo a mão passiva (12h). Finalmente, Andrade propõe o uso de uma versão monomanual do sinal ESTRELA, articulado sobre o dorso da mão passiva (12i).

Figura 12 - Propostas de sinais para os vírus transmitidos pelo $A$. aegypti

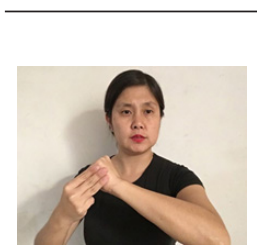

(a)

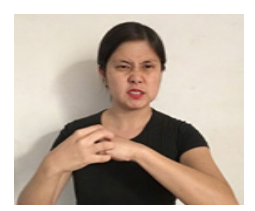

(b)

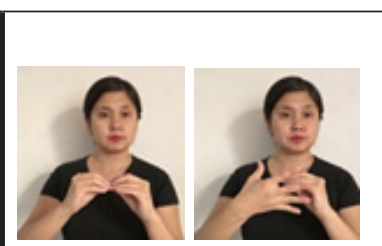

(c)



(d)

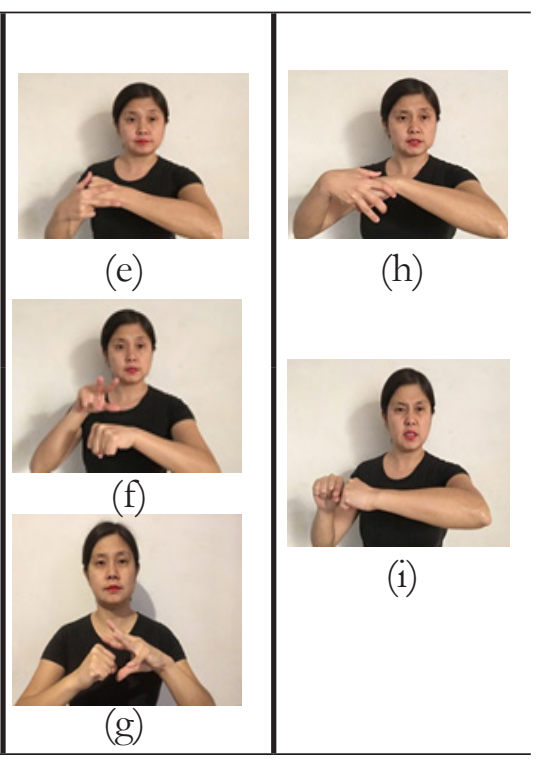

Fonte: Produzida por Cláudia Hayakawa 
Vale notar que tanto no caso do vírus da chikungunya quanto no da dengue (Figura 13), as formas eleitas, (12b) e (12e), respectivamente, foram as mais referidas pelos participantes durante a discussão e, portanto, as mais frequentes no corpus analisado. Para uma síntese da discussão aqui analisada, referimos o leitor ao apêndice deste artigo.

Figura 13 - Número de menções às formas criadas para representar o vírus da dengue



Fonte: Produzida pelos autores

\section{Discussão}

A discussão em análise teve como resultado a criação de sinais para o mosquito $A$. aegypti e para três vírus transmitidos por ele: o vírus da zika, da chikungunya e da dengue. Nesta seção, serão discutidos os fatores que levaram à seleção dos sinais apresentados na figura (14), posteriormente publicizados em um vídeo disponibilizado na comunidade "Sociedade em Libras" do Facebook. 
Figura 14 - Sinais selecionados

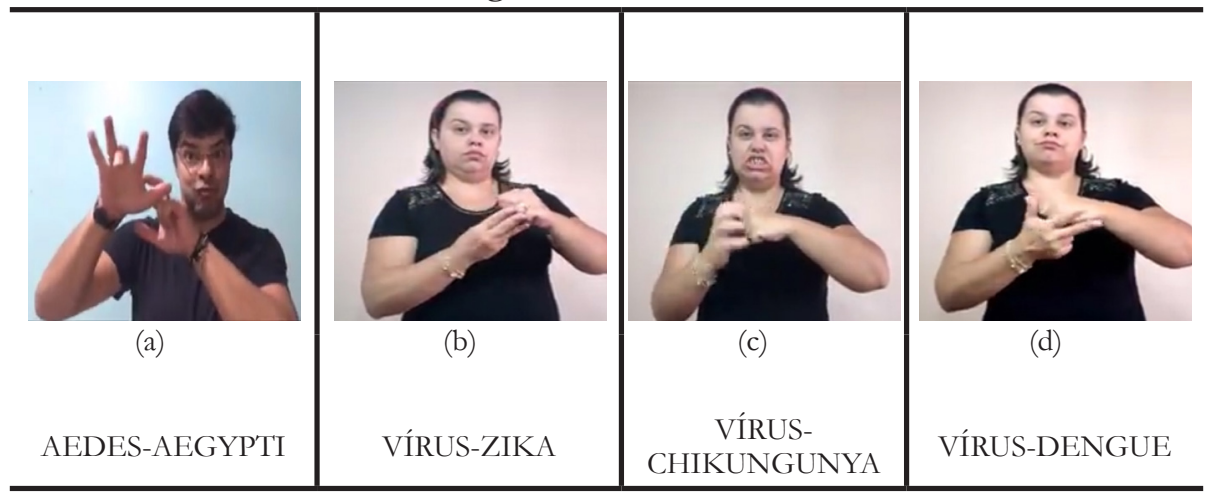

Fonte: Disponível em < https://www.facebook.com/carsalemel/videos/776817169120169/>

Como se viu na seção anterior, a escolha da forma global e/ou da forma dos elementos constitutivos dos sinais em (14) foi justificada por seus criadores pela relação de semelhança entre ela(s) e aspectos visuais do mosquito ou dos vírus. Nesse sentido, pode-se dizer que esses sinais são icônicos e que sua formação é passível de ser descrita pelo modelo de Taub (2004). A título de ilustração, tome-se o sinal AEDES-AEGYPTI (14a). Um exame de sua forma e das circunstâncias em que foi cunhado sugere que sua criação envolveu os mesmos estágios de construção analógica previstos pela referida autora (Figura 15).

Figura 15 - Modelo de construção analógica da iconicidade linguística aplicado ao sinal AEDES-AEGYPTI

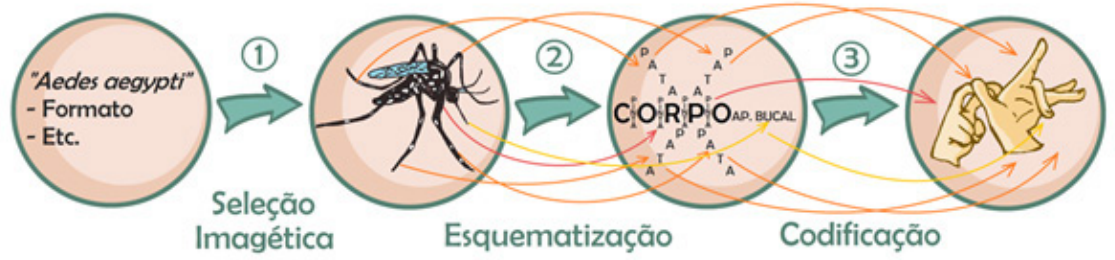

Fonte: Produzida por Luiz Gustavo Paulino de Almeida 
Vê-se que a imagem visual selecionada sofreu um processo de esquematização que, ao filtrar de toda a riqueza de detalhes da imagem original as relações estruturais fundamentais, permitiu codificála linguisticamente e, consequentemente, o conceito a ela associado. Vale dizer que, diferentemente dos exemplos tratados por Taub (2004), nos sinais analisados neste estudo a seleção imagética foi induzida pelo biólogo ouvinte não apenas quando forneceu aos participantes do grupo de discussão imagens do mosquito e dos vírus, mas também quando sugeriu que os sinais fossem criados com base em aspectos de sua forma.

As mesmas etapas previstas no modelo de construção analógica de Taub podem ser inferidas pela análise da forma do sinal criado para o vírus da zika (Figura 14b). Como se pode ver no esquema em (16), toda a riqueza de detalhes da imagem do vírus também foi reduzida a uma estrutura mais simples, constituída por um corpo esférico envolto por uma camada, e linguisticamente representada, respectivamente, pela mão não dominante em $\mathrm{S}$ e pela mão dominante em $\mathrm{M}$ (dedos indicador, médio e anelar distendidos e unidos, e demais fechados).

Figura 16 - Modelo de construção analógica da iconicidade linguística aplicado ao sinal para o vírus da zika

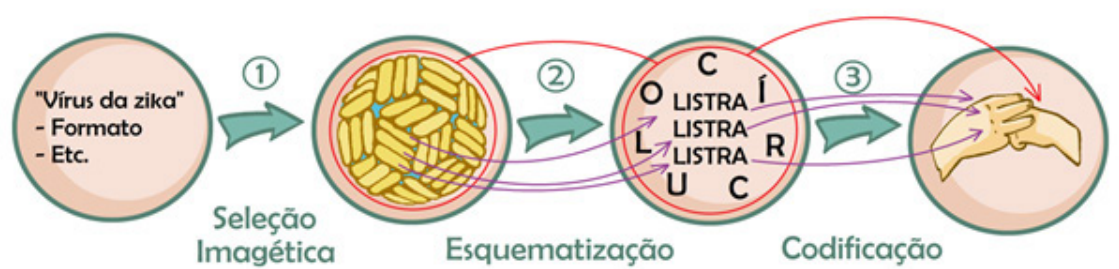

Fonte: Produzido por Luiz Gustavo Paulino de Almeida

Uma evidência adicional de que esse processo de esquematização ocorreu se manifestou na fala do próprio criador do sinal em discussão, quando explicou a motivação dos sinais para os vírus, dizendo que todos 
eles têm o mesmo formato, mas diferem apenas na camada que os envolve (Figura 17).

Figura 17 - Evidência para a esquematização por Koyama

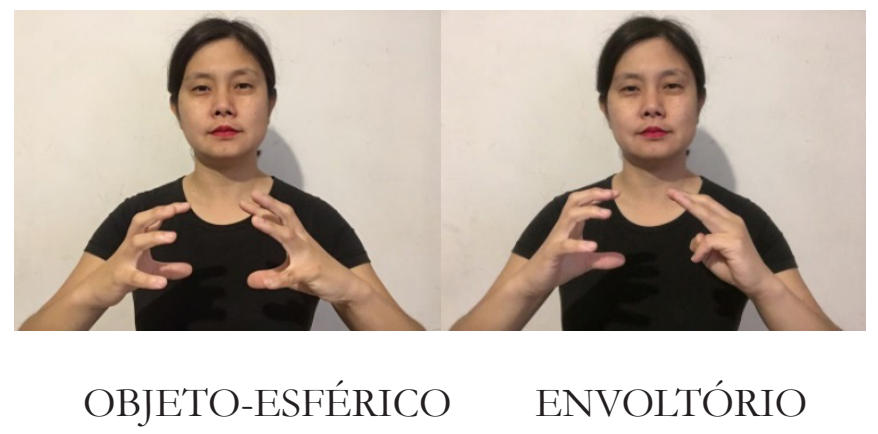

Fonte: Produzida por Cláudia Hayakawa

Reiteradamente, ao longo da discussão, os participantes do grupo fazem menção ao valor do visual no processo de criação de sinais. Entre os comentários, vê-se o de Melendez, que diz "prefiro visual do que letra", aludindo à inicialização, um tipo de empréstimo linguístico que consiste na formação de sinais na Libras a partir da configuração de mão que corresponde, no alfabeto manual, à inicial da palavra escrita do português. Embora, em um primeiro momento, esse comentário possa ser visto simplesmente como uma manifestação de purismo linguístico, sua análise no âmbito da discussão feita pelo grupo dá a ele outra dimensão. Quando Melendez ilustra seu ponto por meio de sinais inicializados que cria aleatoriamente para os vírus da chikungunya e da zika (Figura 17), ele parece estar dizendo que, nesses casos, também há uma perda da visualidade. Em suma, diferentemente dos casos tratados até aqui, nos quais se representam diretamente aspectos da imagem visual associada aos conceitos, nos casos em (17) vê-se uma representação indireta, dado que ela faz referência não ao conceito, mas à forma escrita da palavra do português que o expressa.

${ }^{8}$ Oralização que acompanhou a frase em libras expressa por Melendez. 
Figura 18 - Exemplos aleatoriamente criados por Melendez de sinais inicializados

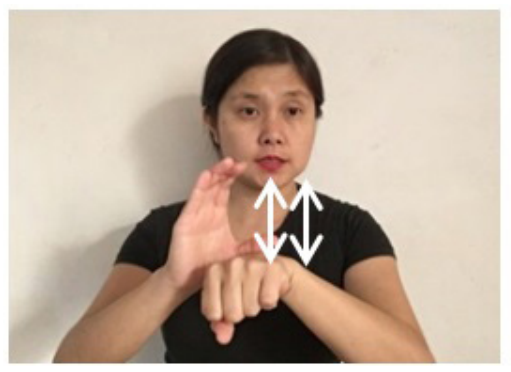

VÍRUS-CHIKUNGUNYA

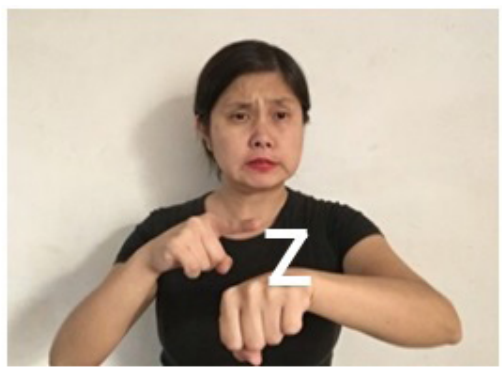

VÍRUS-ZIKA

Fonte: Produzida por Cláudia Hayakawa

A análise de nossos dados à luz do modelo de Taub (2004) revelou dois pontos que, aparentemente, não são capturados por ele. $\mathrm{O}$ primeiro diz respeito à suposta arbitrariedade na seleção tanto dos elementos sublexicais quanto dos elementos lexicais durante a codificação. A despeito do que diz a autora, observou-se, em nossos dados, a influência de fatores de ordem articulatória e perceptual nessa seleção.

Uma evidência disso vem da criação do sinal para o vírus da dengue que, como visto na seção anterior, gerou quatro propostas que diferem entre si basicamente em relação à sua configuração de mão (Figura 19). Além da configuração eleita (dedos polegar, indicador e médio distendidos e demais fechados) (Figura 19a), figuraram, durante o processo de criação desses sinais, duas outras configurações (uma com todos os dedos espalmados e flexionados nas juntas proximais (19b) e outra com todos os dedos espalmados e flexionados nas juntas proximais e distais (19c). Além disso, propôs-se também o uso da versão monomanual do sinal ESTRELA ${ }^{9}$, realizado sobre o dorso da mão não dominante.

9 Tipicamente, o sinal ESTRELA é realizado com duas mãos em frente ao corpo e na altura queixo. 
Figura 19 - Propostas de sinais para o vírus da dengue

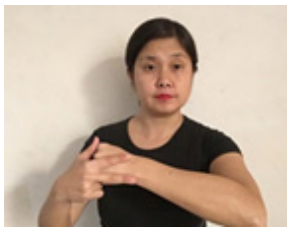

(a)

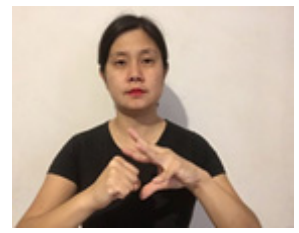

(b)

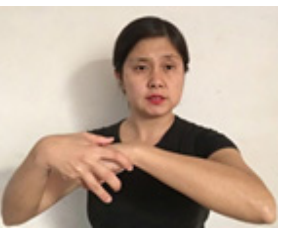

(c)

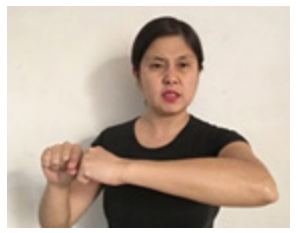

(d)

Fonte: Produzida por Cláudia Hayakawa

Não apenas pelo resultado final do processo, mas também pela frequência de menção durante a discussão, observou-se que a configuração de mão em (19a) contou com maior aceitação do grupo. É provável que isso tenha se dado, por exemplo, em relação à (19b), em virtude de a configuração em (19a) ser mais frequente do que ela (XAVIER, 2006). Somando-se a isso, pelo menos nos dados de Xavier, a configuração em (19b) só aparece em sinais com mudança de configuração: dela para outra em que todos os dedos ficam unidos pelas almofadas. Em relação à forma em (19d), aparentemente ela foi preterida por razões perceptuais. Conversando informalmente com alguns surdos para checar essa hipótese, observamos que é difícil recuperar o sinal ESTRELA a partir da forma monomanual realocada sobre o dorso da mão não dominante, tal como proposto por Andrade.

Fatores articulatórios também parecem explicar a seleção do sinal para o A. aegypti proposto por Nakasato. $\mathrm{Na}$ sua forma original, o sinal continha uma segunda parte, na qual se representava a picada do mosquito, por meio da "penetração" do dedo médio, que representa o aparato bucal do mosquito, entre os dedos indicador e médio (Figura 20). 
Figura 20 - Proposta de sinal para o $A$. aegypti de Naksato

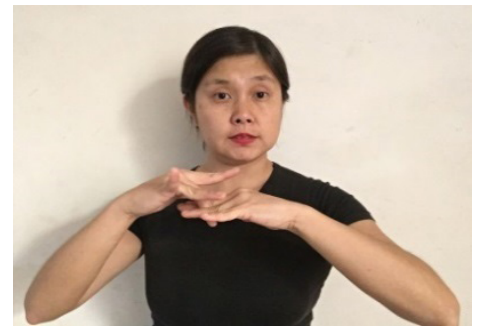

Fonte: Produzida por Cláudia Hayakawa

A respeito dessa forma, Gaspar comenta que ela deve ser articulatoriamente difícil para crianças, provavelmente por envolver detalhes que ela julga desnecessários. Segundo ela, o contato pode ser simplesmente realizado no antebraço e assim, genericamente, expressar a picada do mosquito em qualquer parte do corpo. Alternativamente, ela propõe que se realize com a mão não dominante a configuração de mão empregada por Nakasato em seu sinal para o $A$. aegypti e, ao mesmo tempo, com a mão dominante, a forma empregada por C. Hayakawa que, ao tocar com as pontas dos dedos indicador e médio o dorso daquela mão várias vezes, representa as pintas brancas sobre o corpo do mosquito.

Figura 21 - Propostas de sinal para o A. aegypti de Gaspar

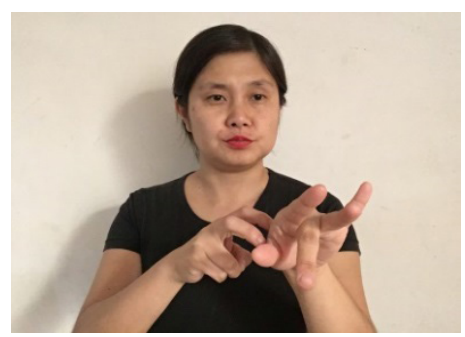

Fonte: Produzida por Cláudia Hayakawa 
No entanto, na visão de Andrade, o sinal proposto por Gaspar é articulatoriamente muito trabalhoso. Ela sugere que se mantenha apenas a forma monomanual do sinal, tal como mostrado na Figura 22, prescindindo-se, assim, do diacrítico que representa as pintas sobre o corpo do A. aegypti. Segundo ela, essa caracterização é desnecessária, dado que o sinal que propõe, por ser novo, automaticamente contrastaria com o sinal MOSQUITO já existente e usado para se referir indistintamente a qualquer mosquito. Essa mesma visão foi expressa por M. Hayakawa, porém acabou não sendo aceita. Como explicou Santos, por pertencer a um gênero que abrange um grande número de espécies transmissoras de diferentes vírus, o $A$. aegypti deve ser distinguido dos demais. Sendo assim, diferentemente do caso do sinal para o vírus da dengue, a precisão conceitual parece ter tido primazia em relação à complexidade articulatória.

Figura 22 - Proposta de sinal para o A. aegypti de Andrade

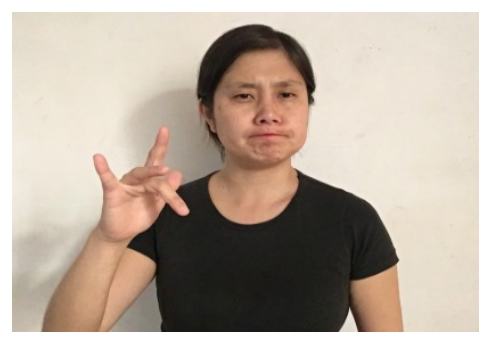

Fonte: Produzida por Cláudia Hayakawa

Outro ponto que parece não ser capturado pelo modelo de Taub (2004) diz respeito ao processo de construção de conceitos. A análise de algumas formas propostas ao longo da discussão revelou problemas conceituais semelhantes aos que a motivaram. Como se pode ver em (23), M. Hayakawa, assim como Andrade, propõe formas compostas para representar os vírus da zika, da chikungunya e da dengue. Por incluírem 
nessas formas uma parte que faz referência à picada do mosquito, nota-se uma indissociação do mosquito e dos vírus que ele transmite.

Figura 23 - Sinais compostos sequenciais para os vírus da zika (a), chikungunya (b) e dengue (c)

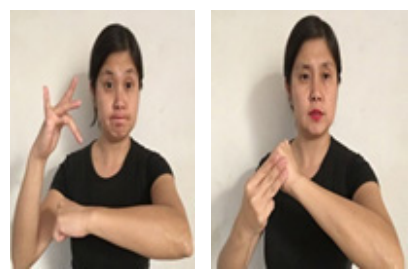

(a)

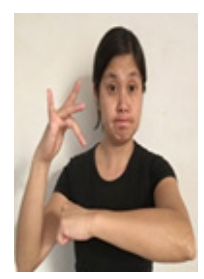

(b)

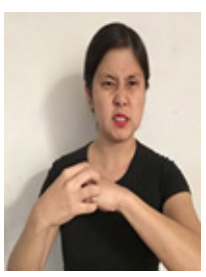



(c)

Fonte: Produzida por Cláudia Hayakawa

Interessantemente, os sinais propostos por M. Hayakawa também indicam outra interpretação de cada uma das mãos nesses sinais. No vídeo em que apresenta suas propostas, ela mostra a mão não dominante e faz sobre ela o sinal de LIMP@ para descrever uma situação em que o corpo não está contaminado pelo vírus/doença. Dessa forma, dissocia tal mão da representação do vírus/doença, diferentemente de Koyama. Em seguida, ao fazer o sinal do mosquito e simular sua picada, indica a contaminação por meio da mão dominante, configurada de maneira a representar o envoltório proteico de cada vírus. Assim, ela restringe a essa mão a representação dos vírus e sugere uma existência dependente entre estes e o indivíduo contaminado. Algo muito parecido pode ser observado nas propostas de Nóbrega. Ele sugere as formas em (24), a partir do sinal MOSQUITO, realizado pela mão dominante, e de configurações referentes a cada um dos vírus, realizadas pela mão não dominante, a saber: em 5 (dedos indicador e médio em gancho e demais fechados) para o vírus da zika (24a), dedos em gancho para o vírus da chikungunya (24b) e dedos indicador, médio e anelar em gancho para o vírus da dengue (24c). 
Com isso, indica também uma indissociação conceitual entre mosquito e vírus. A única diferença em relação ao caso anterior está na forma de composição. Enquanto nos sinais em (23) têm-se um processo de composição sequencial, em (24), tem-se o que Rodero-Takahira (2015) designa como composição simultânea.

Figura 24 - Sinais compostos simultâneos para os vírus da zika (a), chikungunya (b) e dengue (c)

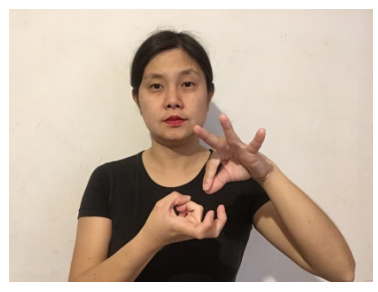

(a)

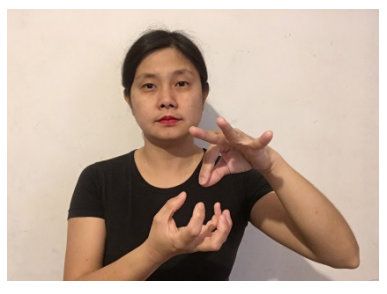

(b)

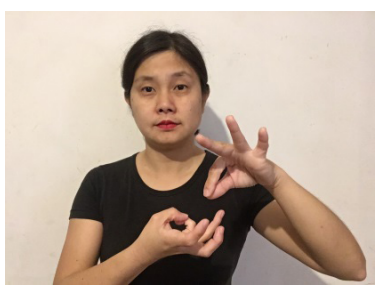

(c)

Fonte: Produzida por Cláudia Hayakawa

A não contemplação desses dois pontos pelo modelo de Taub deve decorrer de pelo menos dois fatos. A autora foca em itens icônicos já criados e convencionalizados, diferentemente deste trabalho que olhou para o processo (e não apenas para o produto) de criação desses itens. Ademais, ela trata da formação de itens icônicos para conceitos como "árvore", "campainha" ou mesmo "formação", relativamente mais simples do que os sinais aqui analisados.

\section{Considerações Finais}

Este trabalho descreveu e analisou a iconicidade no processo de criação de termos técnicos icônicos na Libras, cunhados para designar o mosquito $A$. aegypti e três vírus transmitidos por ele: o da zika, o da 
chikungunya e o da dengue. A descrição e a análise desse processo foram realizadas com base no modelo de construção analógica da iconicidade linguística, desenvolvido por Taub (2004). Segundo a autora, a criação de itens linguísticos icônicos envolve três estágios: a seleção imagética, a esquematização e a codificação, que podem ser entendidos como manifestações de processos cognitivos mais gerais, como a metonímia, no caso do primeiro, e a categorização, no caso dos dois últimos.

Diferentemente de Taub, no entanto, não se tentou apenas inferir os processos cognitivos envolvidos nessa construção a partir da análise de itens linguísticos icônicos convencionalizados. Olhou-se para o processo que culminou com a criação desses itens, a partir da análise de uma discussão que envolveu nove surdos e um ouvinte proficiente em Libras e com formação em Biologia.

Embora o modelo tenha se mostrado adequado para descrever a iconicidade dos sinais criados, dois pontos não são contemplados por ele. Taub acredita que a seleção dos elementos sublexicais ou lexicais para a representação de uma imagem associada a um conceito seja arbitrária. Nos dados aqui analisados, entretanto, observaram-se fatores de natureza articulatória e perceptual atuando nessa seleção. Além disso, por tratar de conceitos como "árvore", "campainha" ou "formação", relativamente mais simples se comparados aos de "vetor", "vírus" e "doença", a autora não levou em conta o processo de formação de conceitos que, como se viu, tem consequências diretas na criação de itens linguísticos icônicos.

\section{Agradecimentos}

A realização deste trabalho não seria possível sem a colaboração de Priscila Gaspar, Alexandre Melendez, Mirtes Hayakawa, Claudia Hayakawa, Cristiano Koyama, Cristiane de Andrade, Ricardo Nakasato, Charley Soares e Valdo Nóbrega. Agradecemos imensamente sua generosidade em 
nos autorizar usar seus vídeos e sua imagem para ilustrar os dados obtidos. Agradecemos também aos professores João Paulo da Silva e Rimar Segala (UFSCar) pela leitura cuidadosa deste trabalho e pelos comentários valiosíssimos que nos ajudaram a melhorá-lo. Por fim, agradecemos a Luiz Gustavo Paulino de Almeida (gustavo.libras@live.com) pelo desenho dos diagramas que ilustram nossa análise de dados da libras.

\section{Referências}

BOYES-BRAEM, P. Features of the Handshape in American Sign Language. 1981. Tese - (Doutorado em Linguística), Universidade da California, Berkeley, 1981.

BRENNAN, M. Word Formation in British Sign Language. Stockholm: Stockholm University Press, 1990.

DEMATTEO, A. Visual Imagery and Visual Analogues in American Sign Language. In: FRIEDMAN, L. A. (Org.). On the Other Hand. London: Academic Press, 1977. p. 109-136.

FAUCONNIER, G. Mappings in Thought and Language. New York: Cambridge University Press, 1997.

HINTON, L.; NICHOLS, J.; OHALA, J. J. (Orgs.). Sound Symbolism. Cambridge: Cambridge University Press, 1994.

KLIMA, E.; BELLUGI, U. The Signs of Language. Cambridge: Harvard University Press, 1979. 417p.

LAKOFF, G.; JOHNSON, M. Metaphors We Live By. Chicago: University of Chicago Press, 1980. 
LANE, H. The Mask of Benevolence: disabling the Deaf Community. New York: Knopf, 1992.

LANGACKER, R. Foundations of Cognitive Grammar: Volume I: Theoretical Prerequisites. Stanford, CA: Stanford University Press, 1987.

LIDDELL, S. K. Paths to Lexical Imagery. Manuscrito, Gallaudet University, 1992.

RODERO-TAKAHIRA, A. G. Compostos na língua de sinais brasileira. 2015. 161 p. Tese -

(Doutorado em Linguística). Departamento de Linguística, Universidade de São Paulo, São Paulo, 2015.

SAUSSURE, Ferdinand. Curso de Linguística Geral. 27. ed. São Paulo: Cultrix, 2006.

STOKOE, W. Sign Language Structure: an Outline of the Visual Communication Systems of the American Deaf. Studies in Linguistics: Occasional Papers, v. 8, 1960.

SYMPOSIUM ON ICONICITY IN SYNTAX, 1983, Stanford. Iconicity in Syntax... (Proceedings of a Symposium on Iconicity in Syntax. Amsterdam: Benjamins, 1983.

TAUB, S. Iconicity and metaphor. In: PFAU, R.; STEINBACH, M.; WOLL, B. (Orgs.). Sign Language: an International Handbook. Berlin: Mouton de Gruyter, 2012. p. 388- 412.

. Language from the body: iconicity and metaphor in American Sign Language. Cambridge: Cambridge University Press, 2004. 


\section{XAVIER, A. N. Descrição fonético-fonológica dos sinais da Língua}

Brasileira de Sinais (Libras). 2006. 175 p. Dissertação - (Mestrado em

Linguística). Departamento de Linguística, Universidade de São Paulo, São Paulo, 2006.

\section{Apêndice}

\begin{tabular}{|c|c|c|}
\hline $\begin{array}{l}\text { Participante: } \\
\text { (O) ouvinte / (S) } \\
\text { surdo }\end{array}$ & Síntese da contribuição & Sinal(is) que cita ou sugere \\
\hline Santos $(\mathrm{O})$ & $\begin{array}{l}\text { Menciona o sinal em (1) em uso por alguns } \\
\text { surdos para se referir ao } A \text {. aegypti e alerta } \\
\text { para dois problemas conceituais. O sinal } \\
\text { revela desconhecimento do fato de que o } \\
\text { mosquito pode transmitir, além do vírus } \\
\text { da zika, da chikungunya e da dengue, o } \\
\text { vírus da febre amarela. Somando-se a isso, } \\
\text { o sinal revela uma não dissociação entre } \\
\text { vetor e vírus, provavelmente motivada pelo } \\
\text { desconhecimento de que esses vírus podem } \\
\text { ser transmitidos, ainda que mais raramente, } \\
\text { por outro mosquito ( } A \text {. albopictus). Por fim, } \\
\text { sugere que sejam criados sinais motivados } \\
\text { por características visuais tanto do mosquito } \\
\text { quanto dos vírus. }\end{array}$ & Figura 1 - MOSQUITO-SAIR-TRÊS \\
\hline Koyama (S) & $\begin{array}{l}\text { Faz menção às imagens enviadas por Santos } \\
\text { para o grupo (uma foto do mosquito } A \text {. } \\
\text { aegypti e dos vírus da zika, da chikungunya e } \\
\text { da dengue) e diz que, com elas, o processo } \\
\text { de compreensão dos conceitos e criação dos } \\
\text { sinais se torna mais fácil. Sugere o sinal em } \\
\text { (2) para o vírus da zika e explica que a mão } \\
\text { não dominante em } \mathrm{S} \text { representa o corpo do } \\
\text { vírus e a mão dominante em M representa } \\
\text { o formato das proteínas em seu envoltório. } \\
\text { Ele justifica a escolha dessa CM, dizendo que } \\
\text { os dedos representam as proteínas dispostas } \\
\text { paralelamente. }\end{array}$ & VÍRUS-ZIKA \\
\hline
\end{tabular}




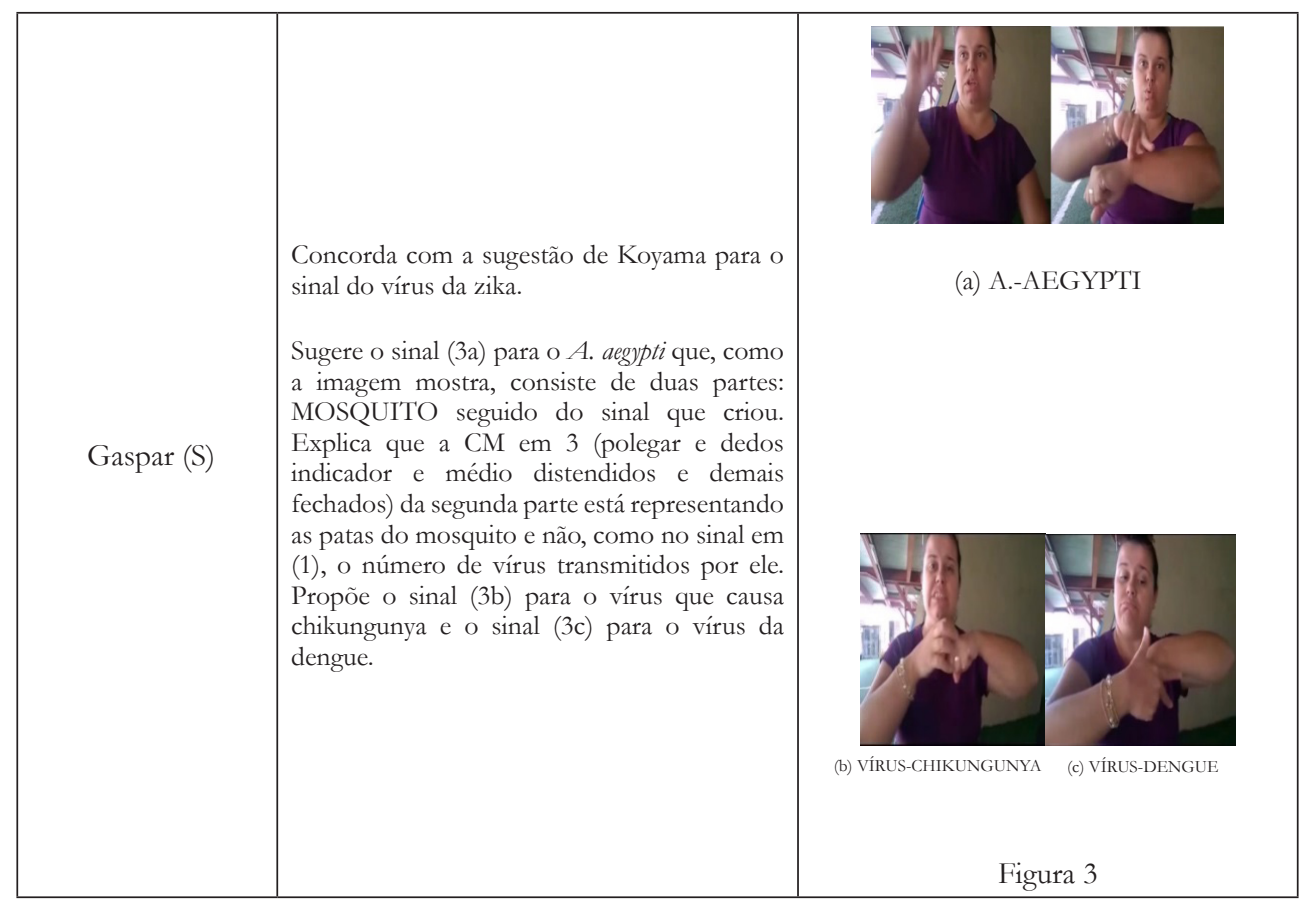




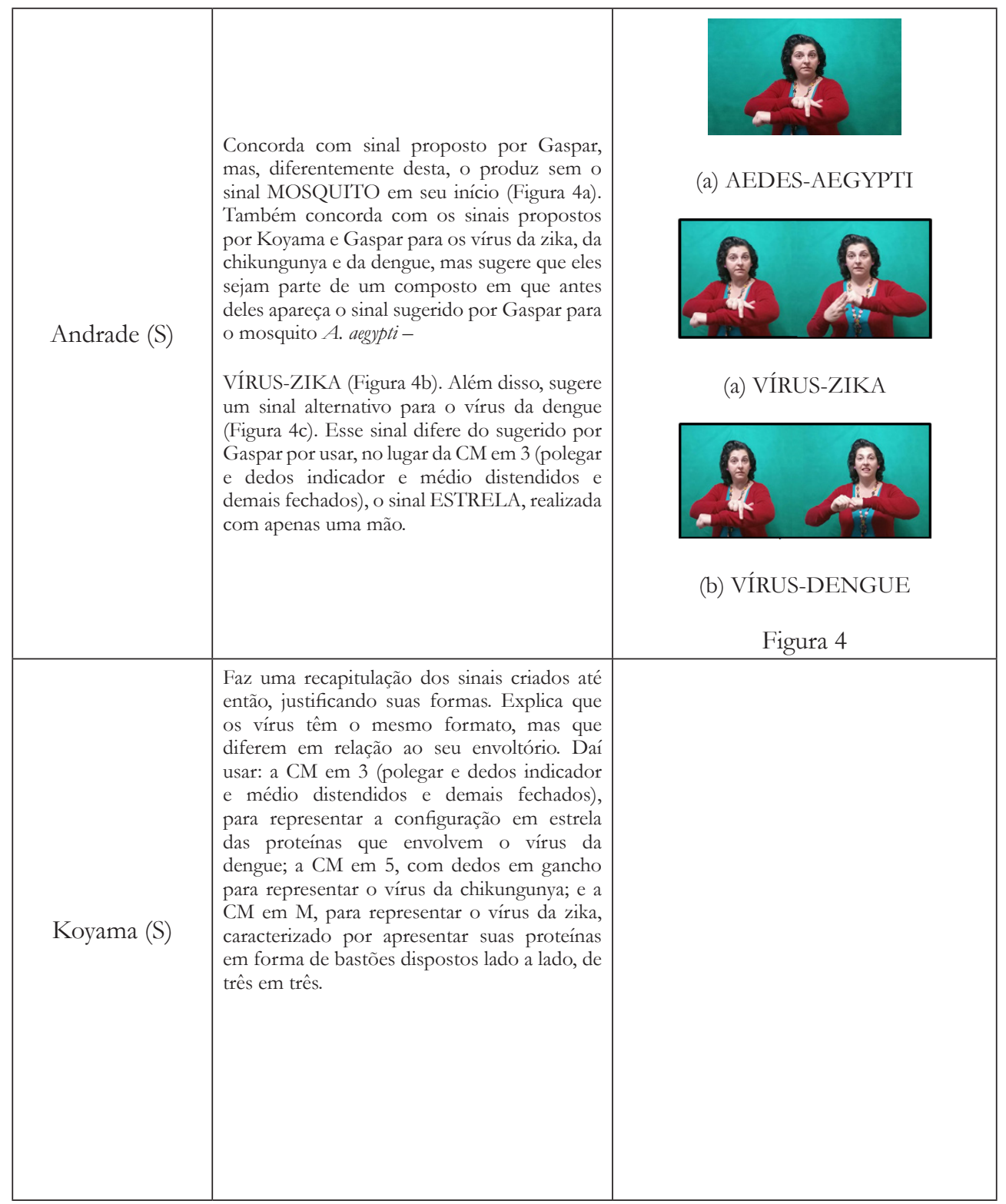




\begin{tabular}{|c|c|c|}
\hline Soares (S) & $\begin{array}{l}\text { Pergunta a Santos se dois outros sinais que viu, } \\
\text { um para a zika (sic) (Figura 5a) e outro para a } \\
\text { chikungunya (sic) (Figura 5b), estão corretos. } \\
\text { Ambos são feitos com a mão não dominante } \\
\text { realizando o sinal MOSQUITO, mas sem } \\
\text { movimento. Eles diferem no fato de que a } \\
\text { mão dominante traça um zigue-zague acima } \\
\text { da mão não dominante no sinal ZIKA e ela } \\
\text { aponta algumas vezes para a ponta do polegar } \\
\text { e do indicador no sinal CHIKUNGUNYA. }\end{array}$ & $\begin{array}{l}\text { (a) ZIKA } \\
\text { Figura } 5\end{array}$ \\
\hline Melendez (S) & $\begin{array}{l}\text { Diz que gostou do sinal para o } A \text {. aegypti } \\
\text { proposto por Gaspar, dado que ele o difere dos } \\
\text { outros mosquitos referidos indistintamente } \\
\text { pelo sinal MOSQUITO. Discorda da correção } \\
\text { feita por Santos em relação aos sinais } \\
\text { apresentados por Soares. Ele alegou que sinais } \\
\text { como os que Soares citou estavam sendo } \\
\text { criados em diferentes regiões devido ao surto } \\
\text { de infecções causadas pelos vírus transmitidos } \\
\text { pelo A. aegypti. Ainda sobre os sinais citados } \\
\text { por Soares, Melendez diz que prefere que eles } \\
\text { sejam icônicos a inicializados (Figura } 6 \text { ). }\end{array}$ & $\begin{array}{c}\text { (a) CHIKUNGUNYA (b) ZIKA } \\
\text { Figura } 6\end{array}$ \\
\hline C. Hayakawa (S) & $\begin{array}{l}\text { Diz que viu a imagem da dengue (sic) e } \\
\text { da zika (sic) e sugere para elas os sinais em } \\
\text { (7a) e (7b), respectivamente. O primeiro } \\
\text { apresenta o sinal MOSQUITO, realizado sem } \\
\text { movimento pela mão não dominante, com } \\
\text { pintas, representadas pelos toques dos dedos } \\
\text { indicador e médio da mão dominante sobre } \\
\text { a lateral da mão não dominante. Já o segundo } \\
\text { apresenta o sinal MOSQUITO, produzido } \\
\text { sem movimento pela mão dominante com } \\
\text { riscas em seu corpo, representadas pela forma } \\
\text { como os dedos da mão não dominante tocam } \\
\text { e se movem sobre a lateral da mão dominante. } \\
\text { Em relação aos sinais para os vírus, concorda } \\
\text { com quase todos os propostos até então, } \\
\text { mas sugere que, no caso do vírus da dengue } \\
\text { (Figura } 7 \mathrm{c} \text { ), se use outra CM (mão em } 5 \text { com } \\
\text { dedos flexionados nas juntas proximais), para } \\
\text { que assim se representem as cinco pontas das } \\
\text { estrelas. Conforme diz, isso não é feito com } \\
\text { a CM em } 3 \text {. }\end{array}$ & (c) VÍRUS-DENGUE \\
\hline
\end{tabular}




\begin{tabular}{|l|l|l|}
\hline Nakasato (S) & $\begin{array}{l}\text { Comenta que, antes das explicações de } \\
\text { Santos, também achava apropriado o sinal } \\
\text { MOSQUiTO-SAIR-TRÉS por não saber } \\
\text { que o A. agypti pode transmitir outro vírus } \\
\text { (vírus da febre amarela) além dos vírus da } \\
\text { zika, da chikungunya e da dengue. Propõe o } \\
\text { sinal em (8a) e justifica a escolha da CM em } \\
\text { 5: dedos mínimo, anelar, indicador e polegar } \\
\text { representam os quatro vírus transmitidos } \\
\text { pelo mosquito ou suas patas; dedo médio } \\
\text { representa o seu aparato bucal (probóscite). } \\
\text { O sinal é realizado com movimento circular, } \\
\text { simulando o voo do mosquito, seguido de um } \\
\text { pouso sobre o dorso dos dedos da mão não } \\
\text { dominante. Após esse pouso, o dedo médio } \\
\text { penetra no interstício dos dedos indicador e } \\
\text { médio, simulando a picada do mosquito. Na } \\
\text { sequência, Nakasato faz os sinais dos vírus, } \\
\text { em sua maioria, muito parecidos com os } \\
\text { sugeridos até então. Ele sugere, no entanto, } \\
\text { duas outras formas para o vírus da dengue } \\
\text { (Figura 8b-c). }\end{array}$ \\
\hline Melendez (S) & $\begin{array}{l}\text { Cita os sinais criados por C. Hayakawa para } \\
\text { a dengue e para a zika e pede a Santos para } \\
\text { esclarecer se mosquito e doença não deveriam } \\
\text { ser dissociados na criação dos sinais. Produz, } \\
\text { assim como Andrade, o sinal de A. aegypti sem } \\
\text { a primeira parte (Figura 4a). }\end{array}$ \\
\hline
\end{tabular}




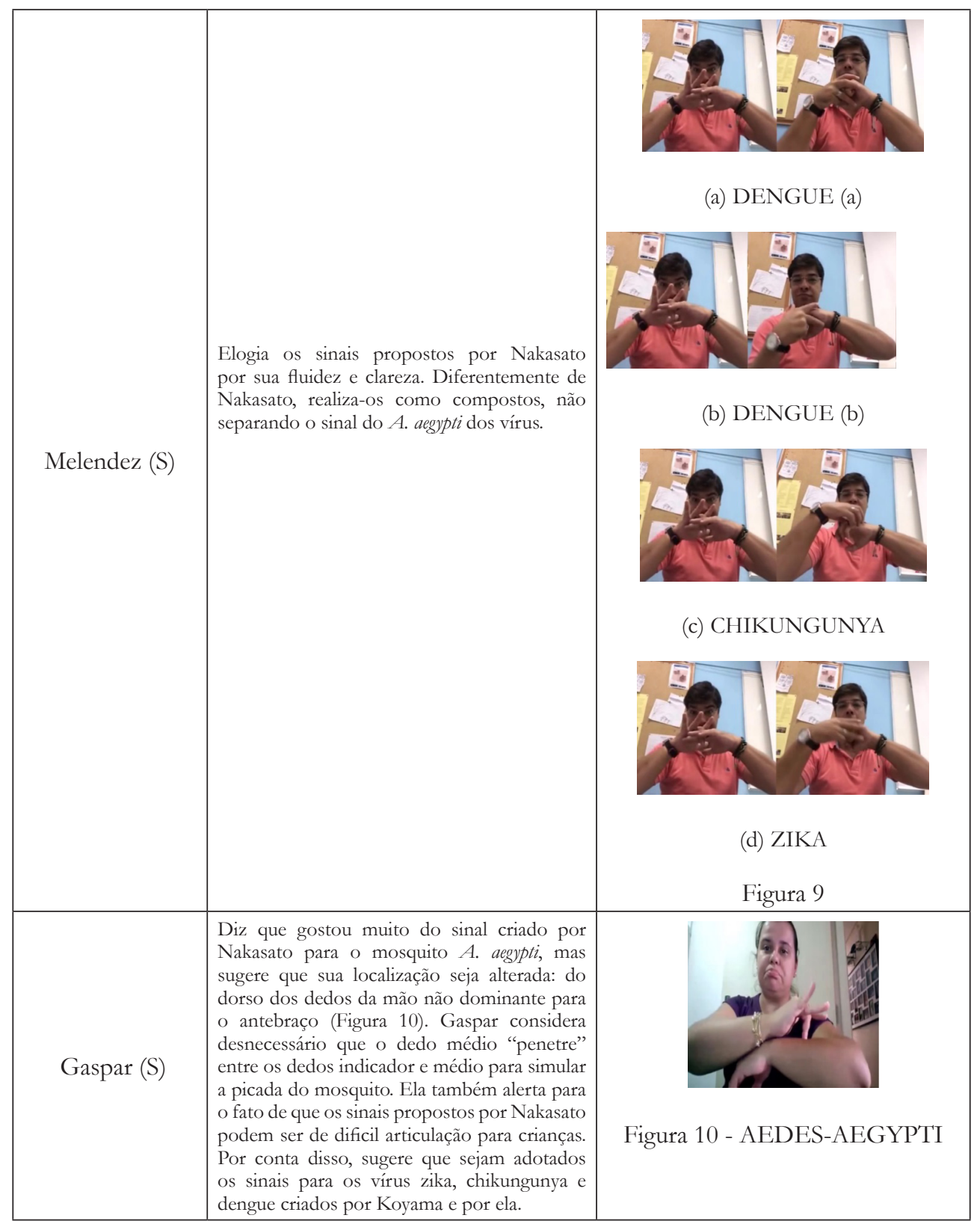




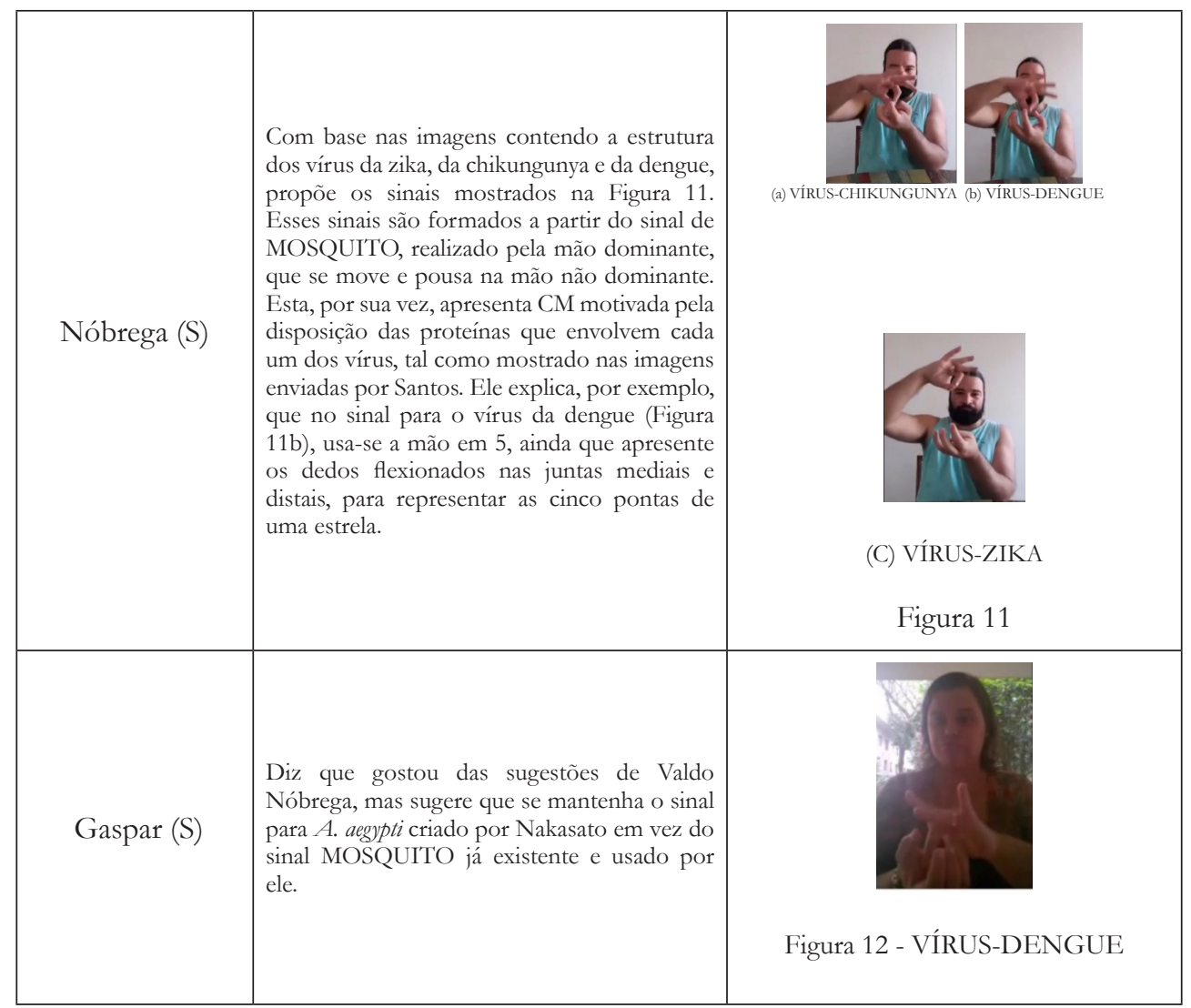




\begin{tabular}{|c|c|c|}
\hline M. Hayakawa (S) & $\begin{array}{l}\text { Comenta os vídeos anteriores sugerindo: } \\
\text { (1) que se substitua a CM da mão não } \\
\text { dominante em O, sugerida por Nakasato, para } \\
\text { S; (2) que se adote o sinal para o } A \text {. aegypti } \\
\text { criado pelo Nakasato; e (3) que se usem os } \\
\text { sinais para os vírus tal como apresentados } \\
\text { por Koyama. Ao mostrar a produção dos } \\
\text { sinais, M. Hayakawa mostra sua mão não } \\
\text { dominante em S, faz o sinal de VAZI@, sobre } \\
\text { ela, seguido do sinal NADA para indicar a } \\
\text { ausência de vírus (Figura 13a). Na sequência, } \\
\text { ela faz AEDES-AEGYPTI-PICAR-VÍRUS: } \\
\text { CHIKUNGUNYA/DENGUE/ZIKA. }\end{array}$ & $\begin{array}{l}\text { (a) NADA } \\
\text { Figura } 13\end{array}$ \\
\hline M. Hayakawa (S) & $\begin{array}{l}\text { Diz que se, no futuro, novas doenças } \\
\text { transmitidas pelo } A \text {. aegypti forem descobertas, } \\
\text { bastará criar novos sinais com base no formato } \\
\text { da estrutura de seu respectivo vírus e juntá-lo } \\
\text { à base já criada (14). }\end{array}$ & $\begin{array}{c}\text { Figura } 14 \text { - Base para formar sinais para } \\
\text { vírus transmitidos pelo } A \text {. aegypti }\end{array}$ \\
\hline
\end{tabular}




\begin{tabular}{|c|c|c|}
\hline Santos (O) & $\begin{array}{l}\text { Esclarece que o sinal criado por Nakasato } \\
\text { para o } A \text {. aegypti não o distingue de outros } \\
\text { mosquitos, dado que todos eles têm corpo e } \\
\text { patas semelhantes. Diz que a sugestão de C. } \\
\text { Hayakawa atende mais a esse propósito, já } \\
\text { que, ao representar as pintas que o } A \text {. aegypti } \\
\text { tem, o particulariza em relação aos demais } \\
\text { mosquitos. Em relação à pergunta de Soares, } \\
\text { esclarece que os sinais não são adequados, } \\
\text { porque diferenciam o mosquito pelo vírus que } \\
\text { transmite. Como se sabe, o mesmo mosquito } \\
\text { transmite diferentes vírus. O mesmo em } \\
\text { relação ao sinal criado por Nakasato e } \\
\text { posteriormente produzido por Melendez e M. } \\
\text { Hayakawa. Ele finaliza sua explicação dizendo } \\
\text { que os sinais a serem criados precisam } \\
\text { dissociar mosquito de vírus, dado que o } A \text {. } \\
\text { aegypti pode transmitir diferentes vírus, além } \\
\text { de ser possível ele não estar contaminado por } \\
\text { nenhum. }\end{array}$ & \\
\hline Gaspar (S) & $\begin{array}{l}\text { Menciona uma situação em que, explicando } \\
\text { para crianças sobre o } A \text {. aegypti, foi mal } \\
\text { interpretada. Segundo ela, as crianças acharam } \\
\text { que o sinal MOSQUITO (1) (Figura 14a) } \\
\text { se referia ao órgão sexual feminino. Isso se } \\
\text { explica pelo fato de ambos os sinais serem } \\
\text { produzidos com a mesma CM. Para evitar } \\
\text { possíveis problemas de comunicação, Gaspar } \\
\text { sugere que se use a variante em (14b). Apesar } \\
\text { disso, reafirma sua predileção pelo sinal } \\
\text { criado por Nakasato e sugere como outra } \\
\text { possiblidade uma junção dele com parte da } \\
\text { sugestão de C. Hayakawa, na qual as pintas } \\
\text { do } A \text {. aegypti são representadas pelo toque } \\
\text { feito pelos dedos indicador e médio na lateral } \\
\text { da mão não dominante (14c). Na imagem, } \\
\text { aparece sinalizando apenas com uma mão, } \\
\text { porque está segurando o celular com a outra. }\end{array}$ & (a) MOSQUiTO (1)(b) MOSQUITO (2) \\
\hline C. Hayakawa (S) & $\begin{array}{l}\text { Expressa sua compreensão quanto à } \\
\text { necessidade de dissociar mosquito e vírus. } \\
\text { Concorda com adotar o sinal em (14c). } \\
\text { Expressa sua concordância em relação aos } \\
\text { sinais criados para os vírus transmitidos pelo } \\
\text { A. aegyptiaté então, mas relembra sua sugestão } \\
\text { quanto à CM em } 5 \text { com dedos flexionados nas } \\
\text { juntas proximais para representar o vírus da } \\
\text { dengue. }\end{array}$ & \\
\hline
\end{tabular}




\begin{tabular}{|c|c|c|}
\hline Gaspar (S) & $\begin{array}{l}\text { Faz menção ao vídeo com os sinais criados que } \\
\text { Melendez começou a preparar para divulgar } \\
\text { nas redes sociais. Alerta Melendez para uma } \\
\text { explicação incorreta que ele dá quanto à forma } \\
\text { de contágio e disseminação da doença. }\end{array}$ & \\
\hline Santos (O) & $\begin{array}{l}\text { Alerta para o papel da mão não dominante } \\
\text { nos sinais para os vírus que estão em } \\
\text { discussão. Ela deve ser interpretada não como } \\
\text { parte do corpo da pessoa picada, mas como } \\
\text { representando parte do vírus. } \\
\text { Dito isso, reforça que é preciso dissociar } \\
\text { mosquito e vírus. }\end{array}$ & \\
\hline Andrade (S) & $\begin{array}{l}\text { Comenta o vídeo feito por Melendez para } \\
\text { divulgar nas redes sociais os sinais que o } \\
\text { grupo criou. Sugere que o sinal para o } A \text {. } \\
\text { aegypti seja como em (15), sem a representação } \\
\text { das pintas como em (14). Ela julga esse } \\
\text { sinal articulatoriamente muito trabalhoso. } \\
\text { Acrescenta que é desnecessário, porque o sinal } \\
\text { é novo e por si só diferencia o } A \text {. aegypti de } \\
\text { outros mosquitos. }\end{array}$ & Figura 15 - AEDES-AEGYPTI \\
\hline M. Hayakawa (S) & $\begin{array}{l}\text { Comenta o vídeo feito por Melendez para } \\
\text { divulgar nas redes sociais os sinais que o } \\
\text { grupo criou. Sugere que o sinal para o } A \text {. } \\
\text { aegypti seja como em (15), sem a representação } \\
\text { das pintas como em (14), dado que é novo } \\
\text { e não poderá ser confundido com outros } \\
\text { mosquitos. Em sua exemplificação de como } \\
\text { Melendez poderia fazer um vídeo mais claro } \\
\text { para o grande público, produz mais uma } \\
\text { vez AEDES-AEGYPTI-PICAR-VÍRUS: } \\
\text { CHIKUNGUNYA/DENGUE/ZIKA. }\end{array}$ & \\
\hline
\end{tabular}




\begin{tabular}{|c|c|c|}
\hline Gaspar (S) & $\begin{array}{l}\text { Reforça, com base na explicação de Santos, } \\
\text { que é necessário fazer o sinal de } A \text {. aegypti } \\
\text { como em (16), pois existem dezenas de } \\
\text { mosquitos do gênero } A \text {. dos quais ele precisa } \\
\text { ser distinguido. Corrige a explicação de M. } \\
\text { Hayakawa quando esta diz que o mosquito } \\
\text { transmite a doença, dizendo que, na verdade, } \\
\text { ele transmite o vírus e que a doença surge } \\
\text { depois. Por fim, alerta para o problema } \\
\text { conceitual envolvido nas formas em (13). Ela } \\
\text { lembra que a mão não dominante em S é parte } \\
\text { dos sinais dos vírus. Sendo assim, o sinal do } \\
\text { mosquito deve ser produzido só com uma } \\
\text { mão, separadamente dos sinais para os vírus, } \\
\text { feitos com duas mãos. }\end{array}$ & Figura 16 - AEDES-AEGYPTI \\
\hline M. Hayakawa (S) & $\begin{array}{l}\text { Menciona a correção de Gaspar e sugere } \\
\text { a Melendez que leve em consideração os } \\
\text { seguintes pontos na elaboração do vídeo de } \\
\text { divulgação: (1) diferenciar a doença do vírus } \\
\text { causador; (2) separar o } A \text {. aegypti dos vírus que } \\
\text { transmite, fazendo o sinal do primeiro só com } \\
\text { uma mão, dado que a mão não dominante em } \\
\mathrm{S} \text { é parte dos sinais dos vírus. }\end{array}$ & \\
\hline Gaspar (S) & $\begin{array}{l}\text { Faz correções em relação ao vídeo que } \\
\text { Melendez fez para divulgar nas redes sociais. } \\
\text { Entre elas, cita a necessidade de fazer uma } \\
\text { distinção entre os vírus e as doenças causadas } \\
\text { por eles. Oferece-se para fazer o vídeo. }\end{array}$ & \\
\hline Melendez (S) & $\begin{array}{l}\text { Concorda com todas as correções e sugestões } \\
\text { feitas por Gaspar, mas contesta que em sua } \\
\text { sinalização não tenha feito a distinção entre } \\
\text { o } A \text {. aegypti e os vírus transmitidos por ele. } \\
\text { Concorda que Gaspar faça o vídeo. }\end{array}$ & \\
\hline Melendez (S) & $\begin{array}{l}\text { Diz que gostou do vídeo feito por Gaspar, } \\
\text { mas adverte que é preciso dizer que o } A \text {. aegypti } \\
\text { pode se contaminar com um dos três vírus em } \\
\text { discussão caso pique alguém contaminado. }\end{array}$ & \\
\hline C. Hayakawa (S) & $\begin{array}{l}\text { Alerta para o fato de o } A \text {. aegypti não ter } \\
\text { apenas duas pintas sobre o corpo, mas várias. } \\
\text { Por essa razão, relembra sua sugestão inicial } \\
\text { de representar essas pintas por meio de vários } \\
\text { toques dos dedos indicador e médio sobre o } \\
\text { dorso da mão não dominante, e não apenas } \\
\text { de um. }\end{array}$ & Figura 17 - AEDES-AEGYPTI \\
\hline
\end{tabular}




\begin{tabular}{|l|l|l|}
\hline Santos $(\mathrm{O})$ & $\begin{array}{l}\text { Reforça a dissociação entre mosquito e vírus } \\
\text { dando alguns exemplos. (1) A. aegypti não } \\
\text { infectado com um dos três vírus em discussão } \\
\text { pica uma pessoa que também não está. Nesse }\end{array}$ & \\
caso, nada de mais acontece. (2) A. aegypti não & infectado com nenhum vírus pica alguém & \\
infectado com um dos três vírus em questão e & passa a ser transmissor de um deles. & \\
\hline
\end{tabular}

